Portland State University

PDXScholar

$5-1-1970$

\title{
Madrona movers; a sociological analysis of a work group as a process of harmony and dissent
}

John Vance Cannucci

Portland State University

Follow this and additional works at: https://pdxscholar.library.pdx.edu/open_access_etds Let us know how access to this document benefits you.

Recommended Citation

Cannucci, John Vance, "Madrona movers; a sociological analysis of a work group as a process of harmony and dissent" (1970). Dissertations and Theses. Paper 207.

https://doi.org/10.15760/etd.207

This Thesis is brought to you for free and open access. It has been accepted for inclusion in Dissertations and Theses by an authorized administrator of PDXScholar. Please contact us if we can make this document more accessible: pdxscholar@pdx.edu. 
AN ABSTRACT OF THE THESIS OF John Vance Cannucci for the Master of Arts in Soclology presented May 20, 1970.

Title: Madrona Movers: A Sociological Analysis of a Work Group as a Process of Harmony and Dissent.

APPROVED BY MEMBERS OF THE THESIS COMMITTEE:

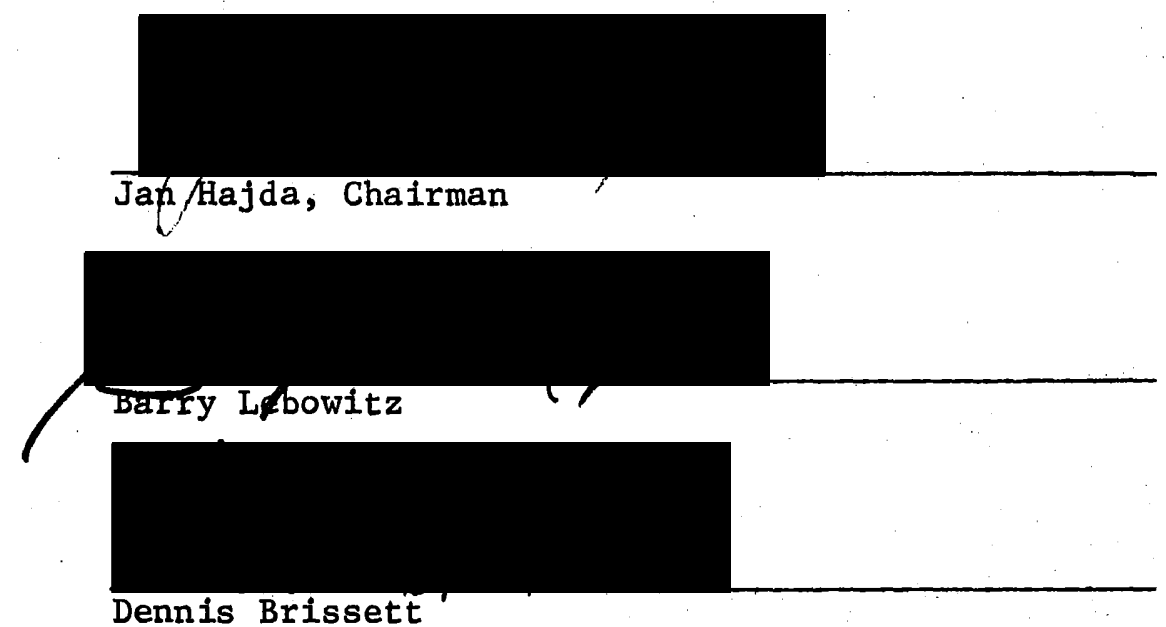

The research problem discussed in the thesis is generally concerned with the investigation of a group of men who work as furniture movers. The problem is focused on the dynamic interplay of status equality and status differentiation as contradictions that render harmony and dissension as common group denominators.

Three questions were asked. First, are there consistent ways of behaving while working as a furniture mover? Second, if consistent ways of behavior do exist, how are they related to the notions of status equality and status differentiation? Third, if this latter relationship should exist, can harmony and dissent be conceptualized as common occur- 
rences?

Four categories of behavior were found to be quite consistent from job to job. They can be described as 'acts.' The acts that were found are coordination, seriousness, humor and advice.

With skill or technique of furniture moving being underlying and related criteria for professionalism, the acts are considered by the movers as being appropriate professional behavior while on a moving job. These acts have both a rigid and a flexible quality. At first glance this statement sounds contradictory; however, it was found that the rigidity of acts arises out of the expectations the movers have while working on a given job, while the flexibility of acts is a result of variations between jobs. These qualities have two important consequences:

First, the workers perceive these acts as important in raising their occupational status with customers. In turn, by working together in establishing these acts (some of which have originated with management and others which have originated from the work group itself), they are defining boundaries for all of them to act within. By acting toward these acts, the workers are compromising formal distinctions which management has imposed, and consequently are nearing status equality.

Second, due to variations in structural characteristics of different types of moving jobs, individual moods, team moods, and customers, the job or situation in which the job is taking place changes. The acts still remain, but the kinds of things that a mover may do with an act changes. This maneuverability with an act offers the worker a chance to do something different from job to job, or at moments during a job. In other words, he may be able to experience status differentiation.

The contradictions of status equality and status differentiation presented in this thesis are discussed in terms of observed alternative lines of action that a mover may choose to initiate. Harmony appears. if the worker chooses to stay with the professional acts while working, 
and, in turn, attempts to realize both status equality and status differentiation through the acts and succeeds.

The acts themselves strain toward status equality and away from status differentiation. Unless a mover was exceptionally brilliant during a job (with both skill and acts), he had a more difficult time experiencing status differentiation than status equality. Hence, a mover dissenting from the professional acts was not an uncommon sight. The worker may feel confined and stifled by not being himself and therefore act too idiosyncratically in relation to what other workers consider to be professional behavior.

Another mode of dissent was observed that arose from the neglect of acts. When this neglect or blockage of the act was apparent, the dissent involved a larger number of movers. The movers would dissent from the acts but for purposes of establishing or re-establishing them.

The movers do not view dissent as being right or wrong, good or bad. Instead, the workers view dissent as both good and bad, right and wrong; it depends upon the context in which the dissent is occurring. At moments, dissent may appear quite natural; at other times, dissent may give rise to fighting, antagonism and sanctioning. Whatever the type of dissent, it is a part of a composite picture of men working together at being furniture movers. Dissent itself is not considered deviant. 
MADRONA MOVERS: A SOCIOLOGICAL ANALYSIS OF A WORK GROUP AS A PROCESS OF HARMONY AND DISSENT

by

JOHN VANCE CANNUCCI

A thesis submitted in partial fulfillment of the requirements for the degree of

MASTER OF ARTS

in

SOCIOLOGY

Portland State University

1970 
TO THE OFFICE OF GRADUATE STUDIES:

The members of the Committee approve the thesis of John Vance Cannucci presented May 20, 1970.

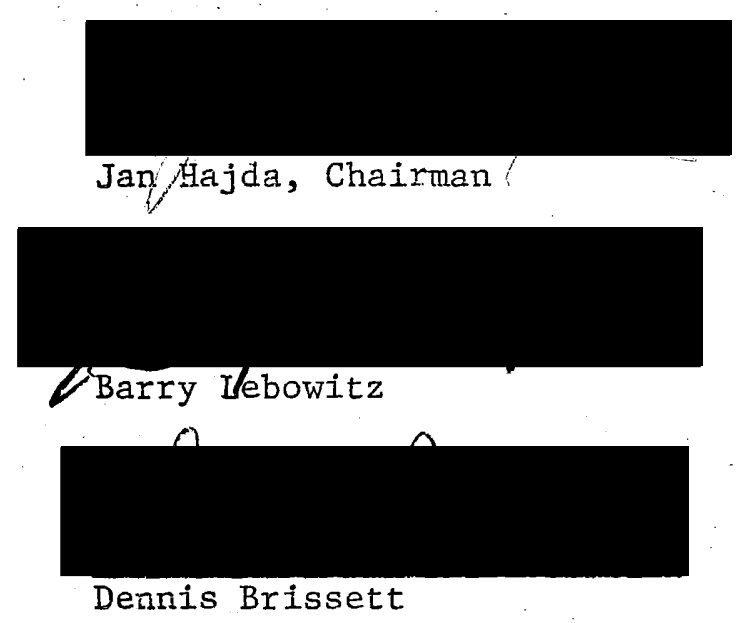

APPROVED :

Charles D. Bolton, Head, Department of Sociology

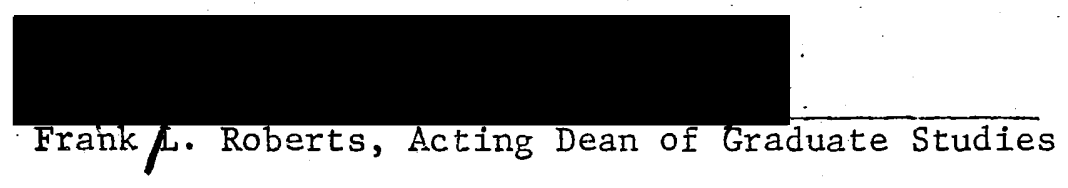

May 20, 1970 


\section{PREFACE}

This thesis is a report of a participant-observation study of a group of men who work for Madrona Transfer \& Storage, Inc.* It is a study that attempts to capture the dynamic quality of working behavior. I worked for Madrona for two summers. My first encounter with this work group was the latter part of June, 1968, when I worked with this firm as a "helper" and later as a "driver," until I entered the master's program at Portland State University in the fall of 1968. At that time I had already begun developing an inclination to study this group of men.

I returned to Madrona as both a worker and a participant-observer in the latter part of June, 1969, and worked until the middle of September, 1969. During participation my main research interests were two: to study the dynamic quality of a small work group, and to study the nature of ambivalence as a determiner of working behavior.

As a student of sociology, I found the concept of ambivalence a fascinating one. Our society has contradictions built into its structure that take many shapes and forms as they enter into the everyday encounters of man. The societal level contradictions that I wanted to study at this micro-level were the counter-tendencies of man's demand for equality and fellowship, and in opposition, his demands to be recognized as a separate and unique individual. Through the ambivalent nature of deciding on a line of action, man is at moments pushed to resolve the ambivalence. He, in turn, becomes an actor and consequently he becomes

*All names and places depicted in this thesis have been changed. 
involved in social interaction where he now has the chance to determine the outcome without participants: they may be in consensus at one moment, and disagreeing the next; each participant, like ping-pong balls, bouncing in and out, desiring to be a part of the group one moment, and demanding to be separated the next; each influencing and changing, and, in turn, being influenced and changed; all being involved in the dynamics of interaction. These are the reasons why I wanted to study a small group of men, and at least, partly, validate the concept of ambivalence as having real and relevant dimensions.

The text of the thesis is broken up into four chapters. The first chapter is a theoretical discussion concerning the informal nature and character of a work group. Included in the first chapter is a theoretical argument on the concept of ambivalence as a bi-polarity of forces that moves man to act.

Chapter II is a discussion on the methods used as a participantobserver. The first part of this chapter is concerried with three basic questions: Why did I want to do this study? What method seemed like a realistic and reasonable approach? Where did I want to investigate? After a brief answering of each question, the remainder of the chapter deals with actual methods that were used while being a participantobserver.

The third chapter is a description of Madrona Transfer \& Storage, Inc. The discussion goes from the company operations, to management, to the working positions, and then to individual profiles of each worker. After the individual profiles, the last two discussions are concerned with the techniques of furniture moving and the customer, 
Chapter IV is blocked off into three related sections. This chapter is the analysis of the findings. It is, as many would say, the "guts" of the thesis. This chapter is the end result of three months of intensive investigation in gathering raw data. The main focus in this chapter is behavior and how a worker's behavior is influenced by status equality and status differentiation.

The conclusion attempts to tighten up the arguments presented throughout the thesis. Included is a brief description of the Madrona work group as having characteristics of other types of groups when the situation varies from working on a moving job to not working on a moving job. Also, there is a statement about the concepts of consensus and dissension as needing further research.

Appendix A is edited field notes as footnotes to Chapter IV. Appendix $B$ is a discussion of my own personal feelings and experiences as a participant-observer. 


\section{ACKNOWLEDGEMENTS}

Many people helped to bring this thesis to fruition: Dr. Jan Hajda, professor of sociology and chairman of my thesis committee, whose encouragement, criticisms, patience, and theoretical suggestions concerning the concept of ambivalence have played a major role through the initial and completed stages of this study.

Dr. Barry Lebowitz, assistant professor of sociology and member of my thesis committee, who, with diligence, patience, and great methodological insight helped me formulate a realistic approach to the study from my own initial grandiose scheme.

Dr. Dennis Brissett, associate professor of sociology and member of my thesis committee, was instrumental in exposing me to a perspective that helped greatly in understanding certain complexities about man's behavior while in the process of writing up the study.

In addition to Hajda, Lebowitz and Brissett, there are others deserving a special thanks who have either directly or indirectly made this thesis possible. Dr. Charles Bolton gave me the opportunity to enter the master's program in sociology, and relieved the pressure of monies by locating and helping me get a teaching position. My family had to suffer the pressures and tensions which are so inherent in the world of graduate students; my wife also had the ghastly task of typing up my first and second thesis drafts. Roslyn MacDonald performed marvelously under extreme pressure to type and proofread the final draft in a relatively short period of time. 
Last, but not least, I want to give a very special thanks to the eight men at Madrona Transfer \& Storage. They provided the data for many of the concepts, and they are the ones that gave birth to this study be simply being people in the fullest sense.

Also, I want to thank myself for having the courage and intestinal fortitude to do a study of this kind, and the moxie to complete it. In an age of computers, where large amounts of data can be easily compiled, statistically analyzed and written up and published-all in a very short period of time--it is nice to have a study that deals with people rather than a statistical entity. On the same token, I take the entire blame for the inadequacies in my thesis. 
TABLE OF CONTENTS

PAGE

PREFACE . . . . . . . . . . . . . . . . . . $i i i$ ACKNOWLEDGEMENTS. . . . . . . . . . . . . . . . . vi LIST OF FIGURES . . . . . . . . . . . . . . . . . . . xi

\section{CHAPTER}

I THE INFORMAL WORKING GROUP: A PROCESS OF HARMONY

AND DISSENSION. . . . . . . . . . . . . . 1

Introduction . . . . . . . . . . . . . 1

Theoretical Background . . . . . . . . . . 4

Work Group Performance: Harmony and Dissent . . . 7

The Worker: Expecting Differences in the Job. . . 11

II METHODOLOGY . . . . . . . . . . . . . 12

What, Why, and Where........... 12

The Method . . . . . . . . . . . 13

The Models and Focusing. . . . . . . . . . 14

The Plan: Jobs, Professional Acts, and Audience . . 14

Participant Observation. . . . . . . . . 15

Third Person Procedure: Overal1 Strategem

Second and First Person Techniques:

Attempts to Verify

After the Fact: Cooling off for Some

Objectivity 
III MADRONA TRANSFER \& STORAGE, INC.: DURING THE

PERIOD OF OBSERVATION. . . . . . . . . . . . . 25

- The Company and Its operations. . . . . . . 25

Family as Management. . . . . . . . . . 28

The Madrona Men: A Profile... . . . . . 34

Furniture Moving: A Degree of Technique and

Skill in Loading and Hauling. . . . . . . . 42

The Customer. . . . . . . . . . . 45

IV HARMONY AND DISSENT: THE ACTION IN THE ACTS--

SOMETIMES NOT ENOUGH ................ . . 48

Introduction: Reading Chapter IV . . . . . . . 48

Section I: Harmony: Status Equality and Status

Differentiation . . . . . . . . . . . . .

The Professiona1 Acts

The Acts: Highlighting Skill and

Technique

The Moving Jobs: A Subtle Routine

Status Differentiation

The Concept of Fit

Change from Job to Job

An Expertise with Acts

Section II: Transition into Dissension: The

Worker as Intentional Actor . . . . . . . .

The Recipient: 'Doing It'

Spontaneous Acts

Section III: Group and Individual Dissent:

Getting Away from the Professional Acts . . . . .

Introduction

The Madrona Group: Reasons for Dissent

Drastic Action: Dissent Away to Establish

or Re-establish the Professional Acts

The Madrona Worker: Reasons for Dissent

Dissent Away: Individual Dissent 
v conCLUSIONS. . . . . . . . . . . . . . . 95

What Has Been Discussed: A Brief Summary . . . . . 95

Is There Any Importance in What Has Been

Discussed? . . . . . . . . . . . . . . 97

Further Research on Harmony and Dissension. . . . - 100

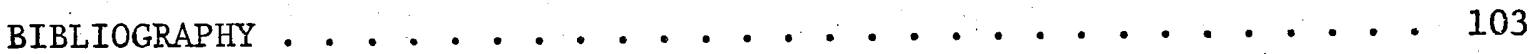

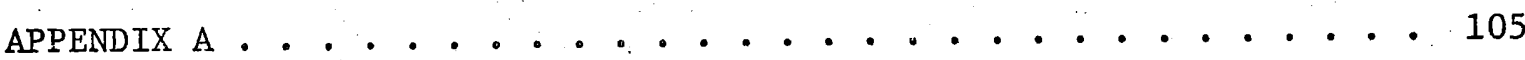

Edited Field Notes as Footnotes

APPENDIX B • . . . . . . . . . . . . . . . . . . . 120

On the Method of Participant Observation 


\section{LIST OF FIGURES}

1. A Moving Job: General Scheme as an Observant Worker. . . . . . . . . . . . 22

2 Formal Organizational Chart of Positions. . . . . . . 30

3 Household Move by Stages with Appropriate Acts and Comments. . . . . . . . . . . 59

4 Office Move by Stages with Appropriate Acts and Comments. . .................. 60

5 A General Relationship between Act Frequency and Type of Move. ................ 66

6 A Comparison of a Worker's Expertise with Each Act by Modes of High, Medium and Low. . . . . . . 67 


\section{CHAPTER I}

THE INFORMAL WORKING GROUP:

A PROCESS OF HARMONY AND DISSENT

\section{Introduction}

The purpose of this study is to examine, describe and analyze a small group process. The small group that is to be presented in this study is what the student of small groups calls a 'working group.' At the formal level the working group i.s formed and organized by the natura of the organizational framework in which the members are performing. There is a hierarchy of role relations that are interrelated to meet the organization's standards of performance and control. This definition is somewhat simplistic when standing alone, for it only recognizes the formal nature of the working group and not the informal. Sherif and Sherif (1966:192) have indicated that the informal group is so widespread and potent within formal industrial organizations that Gardner speaks of it as "one of the characteristics of human organization."

The formal framework offers the members a chance to form informal. relations. The propensity toward the formation of informal relations depends upon the structural conditions of the work. Two conditions are basic in structuring interaction: (1) workers are in physical proximity to each other; and (2) the men are able to interact within the work situation. When these two conditions exist, there is a propensity toward the formation of informal relations. Also, working conditions, such as ease of communication and permanency of relationships, help informal relations 
develop.

Informal relations are defined as those relations that develop between workers to compromise the formal structure of the organization. More specifically, informal relations develop to lessen the depersonalized impact of concrete status distinctions. In most established work situations there are informal groups that may exist counter to or with the organizational setting. For example; the assembly-1ine worker has little chance to communicate with a fellow worker while on the job; he therefore forms friendships counter to the organized work activity. These friendships that form may run counter to the organizational set of standards of work performance (e.g., playing cards, rate-setting, filling-in, etc.).

As mentioned above, though, the organizational setting may be conducive to the development of informal relations; and, hence, there is a constant strain away from status distinctions. The work and informal relations go hand in hand. However, it is not uncommon for this kind of informal work group to run counter to organization, as Gouldner exemplified in Wildcat Strike. Yet, one can not get away from the thought that both, no matter how different, are still attempts at compromising the formal structure. To be concise, this investigation is concerned with the informal work group that fits in with the organizational setting. If a new worker is to benefit from the qualities that an informal group offers, first he must be accepted. To become a member, he must have some awareness of the norms and sanctions of that particular group. As a member, this individual will experience two general tendencies: status equality and status differentiation. On the one hand he experiences the comfort and security of a perceived equality; on the other 
hand he experiences the differentiation which gives him an awareness of autonomy from the other group members. The group norms and sanctions may lean toward either status equality of status differentiation, one outweighing the other--the other thus becoming more difficult to experience. In other words, the intensity of those counter-tendencies will vary from group to group, but no group exists without both. The work group is no exception as any worker soon realizes.

However, no matter how informal a work group becomes, it will never completely escape from the auspices of management; management's rules, regulations and superficial status distinctions will always crosscut the working group's own rules, regulations and status distinctions. Yet, at one extreme, Peter Berger and W. F. Whyte have found 'work groups' that do appear' to be separate from management. Berger (1964:228) states that the informal work group is, at least in part, a 'counter world' created by those expected to work in the world as officially defined by management. Even work with low status and rewards is capable of giving birth to such a world, supplying its inhabitants that measure of satisfaction that almost any social group has to offer. W. F. Whyte (1961a:10) also found a substantial difference between infcrmal working groups and organizational levels:

We found that, however management set up the organization, the people in associating together at work developed a group life which was not entirely predetermined by the formal organization and in fact shaped behavior in ways quite unanticipated by those who designed the organization structure.

other noted investigators such as Blauner (1966), Caplow (1964), Evan (1963), Litwak (1968), and Roethlisberger and Dickson (1939), to mention a few, have related the informal structure of work groups as being conducive to job satisfaction and work performance. The general 
notion being that informal relations reduce strains that arise from the inflexible nature of the existing formal structure. Some of the factors that influence this flexibility are the enhancement of informal commuication lines, release of tensions, informal integrative functions, and establishing behavioral patterns that fit the expectations of both management and worker.

It appears that it does not matter how well the informal work group compromises with the formal structure, it is usually conducive to one thing--satisfaction. However, when one attempts to find out just how informal relations lend themselves to job satisfaction, there is an apparent void of explanation. 'Job satisfaction' seems to be an end consequence of informal relations between workers; however, the process leading toward this end result seems to be somewhat neglected. This investigation is focused on the process as a complicated form of interaction, where harmony and dissent are common denominators of the process. It is hoped that the following discussion will at least partially fill the 'void.'

\section{Theoretical Background}

There is a growing body of theory that establishes the premise that in the modern industrial society contradictions and counter-tendencies are built into the societal structure. These counter-tendencies or contradictions have a tendency to establish ambivalence and ambiguity as essential properties of the modern industrial society. Merton and Barber (1963:95) indicate sociological ambivalence, in its most extended sense, refers to incompatible normative expectations of attitudes, beliefs, and behavior assigned to a set of statuses in a society. Jan Hajda (1968) 
points out behavioral aspects by stating that "ambivalence is the simultaneous presence of contradictory tendencies in behavior. It is an inherent antinomy or bipolarity or co-existence of opposing forces in social as well as non-social phenomena." With the theoretical concept of ambivalence we can separate our perspective from the non-changing quality of a structural-functional perspective. We can perceive the process as something more than merely meeting predetermined expectations with their implied rigidity and conformity of behavior. With ambivalence being a component part of process we can then perceive a dynamic and flexible structure that has the propensity to produce and adapt to change. With the assumption that counter-tendencies exist in life, we have the equally viable assumption that man has alternative ways of behaving in the same situation. In relation to the above-mentioned definition of an informal working group, the counter-tendencies of acting toward status equality or status differentiation can become quite complex in the light of multiple expectations being placed on the worker at both the formal and informal levels. If we take the means-end dimension that is described as a built-in dimension of the modern industrial society, we can assume that ideally it could operate very well at the formal level since the coordination between act and expectation is geared toward a very visible external reward. However, at the informal level, ideally speaking, the consequence of the choice of behavior is not so visible, for it may come during the act or at the end of the act, not before.

With the informal level of relationships still in mind, it becomes apparent that members of working groups are acting toward each other in situations that are clouded with both formal and informal jurisdictions. From this assumption, it becomes even more apparent that the worker who 
is a member of an informal work group is continuously confronted with alternatives, not expectations, that must be acted upon. During an interactional process the individual must be able to choose alternative ways of behaving if he desires status equality or status differentiation. If his choice of behavior has been accepted and/or recognized by others, we have a process where the counter-tendencies of status equality and/or status differentiation have been experienced and/or realized for two important reasons. First, during the autonomous process of choosing between a number of alternative ways of acting, one acquires a vested interest in that choice; how it is received is related to the extent one is demanding status differentiation and/or status equality. Second, by choosing acts that appropriately fit with other acts, there emerges the necessary reciprocity that lends itself to both an awareness of equality and a 'meaningful' experience of differentiation.

At the end of this episode of both choosing and connecting acts, the participants realize a satisfactory experience; an experience that results in the creation of something new or re-establishes the old. This closure has been mutually resolved where all participants may have recognized new things about their and others' behavior, or may have reinforced old thoughts about themselves and others. However, as we begin to examine our particular working group, we are finding that the interactional process and closure are at times problematic and that the demands for status equality and differentiation are not necessarily satisfied. The counter-tendencies of siatus equality and differentiation are in themselves abstractions that may be interpreted as motivational forces that oppose each other and are consequential in producing problems. Because of this apparent abstraction, however, they are, from the actor. 
perspective, more specific or more situational. In other words, the tendencies of status equality and status differentiation are abstract movers that take form in situations by way of defining the situation in regards to appropriate and inappropriate behavior.

On entering a situation where interaction will take place, a person may cope with contradictions like status equality and status differentiation. He might find himself in similar situations yet they are at a slight variance with each other; what is appropriate behavior in one may not be appropriate in another. To cope with the contradictions, he must define away the ambiguity that existed when entering the situation. In other words, these same contradictions that may render one ambivalent, also move people to define and act in a situation. The point here, however, is not only that the counter-tendencies of status equality and status differentiation are demands that must be satisfied, but also they move people to create, change, to act rather than just react; in the process things happen that are exciting, stimulating, and motivating or depressing, frustrating and degrading. This mixture of people's enotions and intellect is the interactional process, therefore rendering actions of harnony and dissent as common occurrences.

\section{Work. Group Performance: Harmony and Dissent}

The discussion in this section is concerned with the notions of harmony and dissent as they relate to work group performance. As meant here, 'work group performance' is a job-oriented activity that involves two or more men that takes place in front of an audience. The audience, from the worker perspective, can be a fellow worker, management, and/or customers. Very briefly, harmony is behaving in a situationally appropri- 
ate fashion. Dissension is behaving in ways that are interpreted by participants as being situationally inappropriate. These definitions, in relation to the ambivalent notions concerning status equality and status differentiation, give rise to a very complex situation in which the worker must perform.

HARMONY: Professional acts, as discussed in this paper, are defined as those acts that are special to a working crew's notion of professional work performance. These acts are simply 'actions' that $a$ worker takes to assure his colleagues, management, and customer that he is skilled. These acts may be common to all of the members of a work group, which, in turn, give them some form of group identity or group status. By the very nature of working together and acting together, the workers are equalizing their statuses. By the fact that these acts are sufficient in number and the workers conceive them as being products of the working group itself, they offer the group members 'specialty acts' so that status differentiation may also be realized.

The workers set limits or boundaries to their behavior in a working situation through a relationship involving workers, audiences; and the nature of the work. These boundaries are to a large part intuitive, which makes it difficult if not impossible to locate the exact range of behavior a worker gives off while working. To a certain extent, these boundaries are ambiguous and, therefore, are minimally observable. This makes it difficult to talk about the workers' 'behavior' as such in a work situation. What happens is that the workers have established certain guideposts to direct their behavior. Even though the guideposts do not control all behavior in a work situation, they do offer enough restrictions so that the work group's collective notion of professionalism 
may be upheld in a work situation. Also, there are a sufficient number of guideposts that are not specifically defined and vary from job to job; a worker may gain status and differentiate himself by specializing in these acts and knowing the proper moment to use them.

The guideposts, or acts as they will be called from here on, may have the potential of handling the contradictions of status equality and status differentiation. When this potential is realized through the acts, they will be considered professional acts. If one was to choose an act and do it at an appropriate moment, and then be responded to in an appropriate fashion, then this would be considered 'in harmony.' However, in an actual job where you have relationships between worker-worker and worker-audience, which have a likelihood to be qualitatively different, you have problems in not only choosing the proper act but also fitting the act into the situation so that you do not overstep the boundaries of appropriate behavior. The boundaries of appropriate behavior do vary from situation to situation; this, in turn, implies the difficulties that a worker may encounter by staying in harmony with the situation.

DISSENT: An interesting notion concerning dissent is that it does not wholly mean deviant behavior. There are instances where it takes the apparent form of re--establishing traditional structure. Even though the 'professional acts' may take on the appearance of a 10osely defined structure, they are still important in establishing boundaries for human behavior. The acts have proven themselves over time as means of experiencing status equality and status differentiation. If something obstructs the workers in being able to play at these acts, the workers may monentarily dissent to rid the situation of that obstruction. How-. 
ever, that is only when all or a large part of the membership know what is causing the obstruction. This is termed group dissent. This is an occasion where they may be considered 'sanctioned offenders'; they may act unprofessionally to establish or re-establish professional acts.

However, the acts themselves may give reason enough for dissenting from them. The acts may be structured so that status differentiation is difficult to experience. A worker may feel confined, or the act may be structured so that acting them out offers no real challenge. A worker may feel bored; in turn, he may simply dissent from the professional acts and become an unsanctioned offender. This is termed individual dissent.

Individual acts of dissent may take three general forms. A worker may intensify a professional act beyond the boundaries of what is considered by the rest of the working men to be situationally appropriate. The second form of dissent may be the result of the ambiguous nature of certain acts and situations rendering the selection of appropriate behavior problematic and in turn a worker may act 'out of place.' The acts, although flexible, may in certain situations cause a worker to feel confined and he may have an urge to separate momentarily in the form of behavior that is considered too idiosyncratic. Each of these forms of dissent is linked by an overriding notion that each is a stepping-out process. In other words, 'acting too much,' 'acting out of place,' and being too 'idiosyncratic' are all forms of stepping-out of boundaries that are either pre-supposed or built-up during a work performance. 
The Worker: Expecting Differences in the Job

Boundaries are pre-supposed by the very notion that a work group has professional acts: some specific, some not so specific. Before beginning a job, each team member is more aware of what behavior is not allowed and to a lesser degree what behavior is allowed. For instance, the worker may realize that he should not be depressing, nor should he be authoritative by giving orders. The worker who is depressing, or plays, or gives orders, for example, may be ridiculed for these actions by fellow workers. The implications are that informally the workers do not tell each other 'how to act,' instead they imply proper behavior by telling each other 'how not to act.' They do not say that giving advice is allowed, but they do say that "giving orders makes us look like animals rather than men." Hence, even before a team begins a job, they are to a degree aware of appropriate and inappropriate behavicr, and therefore boundaries are to a certain extent pre-supposed.

However, each job can be slightly different; or, more accurately, a worker may expect differences in each job. The crew expects differences in themselves, others, and structural differences between jobs. By expecting differences, the workers are establishing flexible boundaries to the on-coming situation in which the job will take place. Each job is a process where workers and audience feel each other out, especially the workers who have more to gain if they can accurately interpret audience behavior. Hence, there is a process where the situation is being defined so that boundaries may be built-up and around all the participants--workers and audience. In this manner, pre-existing status distinctions between worker-audience may be removed. 
CHAPTER II

\section{METHODOLOGY}

\section{What, Why, and Where}

After being exposed to a large dose of small group research while in. the attempt of seeking out answers to bothersome questions, I decided that I was getting nowhere. Most of the research that I was exposed to was conducted in laboratories where the researchers attempted to control variables and experiment with others. The researchers looked at change in structure, communication networks, leadership, performance, and at times did hint at an awareness of the 'follower.' It was his latter component of a group that prompted particular questions that in turn initiated a hunt for relevant information, which, as stated before, was like filling a large empty void with two or three grains of sand.

Hwever, after reading the works of two men in particular, William Foote Whyte (1955-6) and Herbert J. Gans (1962), three questions began in part to be answered. The first question concerned whether a group member was really anything but a stagnant; hollow, sterile being. After reading Whyte's Street Corner Society, and Gans' Urban Villagers, it became apparent that the group member is something more than a puppett. A group nember is more of an actor than a mere respondent--one who is constantly acting, therefore presenting himself in some ways as dynamic. These readings helped confirm a few of my own findings that I had in relation to some group experiences. 
The second question concerned itself with the place that I would want to conduct my research. This question was not solely answered by the works of Gans and Whyte; instead, it had been in my mind for quite some time. However, it was after reading the studies done by these two investigators that the place began to unfold as a realistic arena. Madrona Transfer \& Storage, Inc. seemed to hold all of those ingredients that are necessary to a one-man investigation of a complex problem in a short period of time.* It was also convenient; it was close to home and I could work and make money while attempting to be a participant observer.

\section{The Method}

The third question that was answered concerned itself with the method of investigation. In the studies I read, those that seemed to be near my perception of member interaction were done by participant observers. At least, in part, this method seemed to be the one that could catch the dynamic quality of the small group process which I wanted to describe and explain. By participating in a small group, it appeared that not only can one observe the more overt behavioral characteristics, but also by participating one can become more sensitive to the more covert things that go on within a group. It occurred to me that with this heightened awareness, one may be able to get a handle on the subtle dimension between 'what ought to be' and 'what is.' It appeared that participant observation would be the most unlikely method to render damage to the naturalness of the situation, as compared to the methods of using questionnaires, structured interviews, and/or just simply observ-

*For a more detailed description of MADRONA TRANSFER AND STORAGE, refer to Chapter III. 
ing. All of these reasons added up to the fact that participant observation was in and of itself the best method for a study of work behavior.

\section{The Mode1s and Focusing}

With all of this in mind, I began to orient myself towards a unit of observation that would help explain what made the Madrona worker a dynamic actor. I found that a symbolic interactionist model gave me a episodic dimension of interaction which would be especially helpful in my investigation and explanation. An episode of interaction has a beginning and a closure; for instance, in taking two interactants, you can observe them entering into an episode, its continuation, and eventually its closure. I also found the works of Erving Goffman helpful in orfenting me toward a dramaturgical viewpoint that would help me focus on the Madrona worker as an actor and other participants as an 'audience.'

\section{The Plan: Jobs, Professional Acts, and Audience}

At the moving end of the operation the moving jobs have a beginning and an end. This would be an added advantage in that each job could be blocked off into separate episodes. Also, in categorizing these jobs over a period of time, I would be able to locate consistent acts between them. In other words, each episode of interaction does not stand isolated, but may be related by consistent patterns of behavior. I hoped to locate and isolate the most common acts that were conducive to the worker's performance as a professional furniture mover.

Since the units of observation are episodes of interaction and the work group members are interactants, I then needed indicators of dissent and harmony. To observe and interpret these as explicitly as possible, I 
decided to concentrate on the acts that were directly related to the profession of furniture moving. I felt that if my theoretical assumptions were correct, the professional acts should contain the capacity for workers to realize both status equality and status differentiation.

By the fact that I was going to concentrate my attention on the Madrona crew working on jobs, I added another dimension to the investigation--the audience. The audience, I decided, would be both customers and the management. In other words, the relationship between workers and workers, workers and audience, would be highly important in explaining acts of dissent and acts of harmony.

\section{Methodology: Participant Observation}

The words participant observer imply a standpoint that views social activity from a second person perspective. In other words, you are there but never fully engaged or disengaged. Some kind of 'happy medium' is the ideal viewpoint of a participant observer. However, in this investigation the third person and first person were also utilized, the third person appropriately fitting into the procedure as an overall stratagem: in other words, standing back, disengaged from the activity and generalizing over the activities that were to be observed and those that had been observed. The second and first person were techniques that were utilized while participating in the work and work-related activities.

As a participant observer, I ran the continum where observer is at one end and participant at the other. In turn, the recorded data ran from objective generalizations to subjective experiences. 


\section{Third Person Procedure: Overall Strategem}

TIME BLOCKS: In order to gain some kind of general structure and objectivity in the investigation, two time blocks were devised. Generally the time blocks were set up to impose arbitrary time limits on the investigation. Specifically, each time block contained its own function or purpose: the intended purpose of the first was saturation and focus was the purpose of the second time block.

The purpose of the first time block was to find and isolate consistent acts of harmony and dissension. Generally, this task was to be accomplished by comparing the worker's concept of a 'good move' and 'bad. move.' This time block was a saturation phase where everything that one could observe while working, no matter how trivial the thing may have seemed, was recorded. The categories in this first time block were 'type of job,' 'team members,' 'activity on the job,' and the important 'residual category.'

Within the first time block 'type of job' was the primary category. Under this category the two categories of 'team members' and 'activity on job' were developed. This is not saying that 'type of job' was any more important than the other two; instead, it merely implies a taxonomic scheme that would allow one to saturate with data. The outcome of this saturation would be consequential in locating relationships between the three categories, or non-existing relationships between the three. There-

*The concept of 'good move' and 'bad move' during the participation period was so at variance among the workers that it was discarded for the sake of concentrating on the acts. There was only one recorded move that was considered a 'good move' by all of the involved workers and that will be discussed in APPENDIX A. 
fore, from these three categories several relevant questions had to be answered before continuing into the second time block.

1. Do the different types of jobs affect the kind of activities that take place when the combination of men remains the same?

2. Does a different combination of men affect differences in the kinds of activity that takes place when the type of job remains the same?

3. Taking the variations of types of jobs and combinations of men working on a job, are. there activities that remain fairly consistent?

The category of 'activity on job' involved everything from degrees of skill, degrees of teamwork, jokes, customer relations, arguments, friendliness between participants, personalities, and thoughts concerning themselves and the customer before, during, and after the jobs. From this conglomerate of bits and pieces, skill was expected as an important act. However, even though skill as a measurement of professional status is important, the time block's primary purpose was to collect consistent behavioral patterns as professional acts.

The purpose of the second time block was to focus on those consistent behavioral patterns that were found in the first time block and find out how they relate to harmony and dissension. It is in this phase that the term 'acts' was brought in to replace 'consistent behavioral patterns' for reasons of observational convenience and descriptive power. More importantly it was during this second time block that three general questions were to be answered under each of the two main categories.

\section{Harmony}

1) How do the acts relate to status equality?

2) How do the acts relate to status differentiation?

3) What is harmony? 
Dissension

1) Do the acts have anything to do with dissent?

2) Who are the important recipients of the act?

3) What is dissension?

At least these were the initial questions that would mark entrance into the second time block. They, of course, would be breeding grounds for many more questions as one "marched down the methodological road of participant observation"

COMPARISONS: Once embarked into the second time blöck, comparing past and present job circumstances would be highly important. It consists of comparing worker behavior in front of two different audiences (management and customer), and without an audience. Also included was the subtle comparison between information received from different informants and seeking out contradictions that either meant a different interpretation of a particular event or that an informed informant was puttingon the participant observer.

However, it was expected that the most important source of information would be gathered when comparing worker behavior in front of either an audience or no audience. If there were 'acts,' it was assumed that they would be more intensified in front of an audience. Not only would this comparison act as a means of verifying those acts that had been found, but also in finding out how they work. The closed episodes that were felt to be most important in this comparison were when the workers, as a team, were involved in warehouse storage (no audience) and regular moves (audience).

NOTE TAKING: Participant observation is note taking. Yet, as participant observation can take on a variety of forms, so can the 
inherent note taking. Since this investigation is based on authenticity, being present with note pad, tape recorder, or any other record taking device would seem to contaminate the authenticity of the situation even more than my presence already had. A decision was made under the cliché of "out of sight, out of mind," which meant that note taking would take place at home or any other place (e.g., bathroom) where workers were not physically present. Another reason for taking notes in such a fashion was that it would be quite an inconvenience to simultaneously carry a chair and take notes, since I would not only be an observer but a participant as well.

With this kind of note-taking procedure, it is quite apparent that the memory would have to be heavily relied upon. The human memory, of course, is not the most accurate nor objective of things that can maintain and hold incoming data, Just by the mere fact that a time lapse would be evolved between the time the behavior was observed and the time it was recorded would make one suspicious of its authenticness. For this reason techniques were devised to help verify the incoming and recorded data, to help and to supplant the third person viewpoint.

\section{Second and First Person Techniques: Attempts to Verify}

INFORMANT: Informants are persons related to the Madrona firm in any form. The most frequent informants were the workers themselves, with management coming in a close second, and union officials a long third.

Generally, the informant would be used as a means to cross check recorded information. This would be done in a personal manner. This manner simply involved questioning a person indirectly about some information that was gathered from another party. Or questioning an event that 
both $I$ and the informant had been involved in, or an event that I had not taken part in but wanted some information about.

The approach would not involve a pattern of questioning that directly referred to the past event, but instead a questioning that directly lead into the pas event as a 'source of interest.' In this way the participant observer is not set up as a 'busy body' who was always asking questions that may or may not concern him. Instead the flow of conversation with an informed informant would lead into the 'point of questioning' as a 'source of interest' for both the participant observer and the informed informant. Consequently this kind of approach instills a relationship between participants rather than a relationship between observer and participant.

INTERVIEW PLACES: Interview places tie in directly with the informant approach; the informed informant technique was utilized. Interview places are work related; they are places that do not contaminate or have the potential to change greatly the worker's behavior.

Interview places are a direct part of the worker's occupational life style that is exemplified by informal relations and realized in the activity of teamwork and a sense of fellowship. Any place that contaminated or changed this sense of fellowship was excluded as a place where the informant could be used. For instance, the worker's home was not used as an interview place since it was too disjointed from the work situation (on the part of the worker, there was a constant avoidance of home-related discussions).

There were three places that were quite popular and used frequently in establishing a dialogue between the Madrona workers and myself: 
1) Lunch Room: used before work to talk about the prior day's events.

2). Truck Cab: used during the working day to talk about our move and anything else bothering the worker and the participant observer.

3) Tavern: utilized after working hours to attempt to sum up everything that had happened to other workers, simply to drink, and to entertain ourselves.

This represents a long day, but more important, of course, is the continuity and propinquity between the places and the related events of that day. Generally, this was a continuity and propinquity that helped confirm incoming data.

EPISODES: Up to this time the techniques have been focused on the verbal participant--'the questioning worker'; however, as yet, there has not been any mention of the techniques used as the 'observant worker.' One of the techniques used in this investigation was blocking off activities into episodes. At Madrona there are a number of different activities that a worker may partake of. Each activity would have a special name (warehouse, office move, local move, etc.) and be blocked off with an entrance and a closure. These episodes had definite beginnings and definite ends and were called 'closed episodes.' The majority of findings for this investigation were drawn from the 'closed episode.' It is the 'closed episode' that this thesis emerged from; therefore, this discussion will center on the 'closed episode.'

At first the closed episode is merely that; it is not distinguished by on-going activity--it is distinguished only by its 'special job name.' The 'observant worker' takes mental notes of everything he possibly can. The only structure in the first time block is the episode's beginning and end. This is sort of a familiarization period for the participant 
observer; before you can ask relevant questions, you had better know how and what to ask. After the familiarization--saturation period--the activities begin to take on structurally different characteristics that reduce an observant worker's range of focus and increase sensitivity toward the specific acts that have been found in comparing closed episodes. Note taking increases in depth, relevant questions begin to emerge, and the observant worker becomes more 'professional.'

The episodic dimension also involves a process of interaction that does not remain constant from beginning to end, but changes. Taking this perspective from the episodic dimension and using it on jobs became quite helpful after the saturation phase (First Time Block). Going on the premise that changes in a job are probable, I began to concentrate on three phases of a job and their relationship to the professional acts. For instance, I chopped a moving job into three phases: an entrance, the middle, and the end. From the 'observant worker' viewpoint I was able to concentrate more fully on the job as a whole by this simple seg-. mentation. Below is a sample of the general phases and the kinds of questions that were asked in relation to each phase.

Figure 1: A Moving Job: General Scheme as an Observant Worker

1. What acts are important here?

2. How is the customer dealt with?

3. How do the team members relate with each other? 
This is a composite picture of all the types of moving jobs. Its importance lies in the methodology of being a participant observer. The analysis in Chapter III will treat these phases in more detail.

EMOTIONAL GROOVE: This, of course, is the most subjective technique. So far there has been a description of the 'questioning participant' and the 'observant worker,' both of which hint at a functioning on an objective-subjective dimension. Yet, both the 'questioning participant' and the 'observant worker' suggest more objectivity than subjectivity on the part of the investigator. However, this investigation is also focused on a concept called group experience. For instance, status differentiation connotes a certain amount of individualization: a certain amount of awareness on the part of the workers as a separate being. Status differentiation, as one side of the group experience, can be partially observed and partially subjectively felt by being a participant observer; however, to reach a full experience, you must, at times, become a 'worker.' To become a worker in the fullest sense, you must set yourself into those moods that are known to that particular group. The participant observer does not become a worker by merely becoming involved; he becomes a worker when he gets caught, intentionally or unintentionally, in an emotional groove. Objectivity, any part or partial, is momentarily lost for the sake of commitment: you hate, you love, you demand, you are lonely, you act and you influence. You do all of these things that are taboo to the ideal participant observer's role. You become specific at these moments; your data become, in essence, totally experiential. 
After the Fact: Cooling off for Some Objectivity.

This method was incorporated into the scheme after the period of participation in the Madrona work group. Analysis of the data had gone on while participating and observing. However, the greater part of analyzing the data went on afterwards. In relation to the problems that were involved in this investigation, I made a decision concerning the level at which the data would be discussed; I would have to be more general than specific. To accomplish this; I had to 'cool off.'

After spending a mere [sic] three months with the men at Madrona, I found myself having a difficult time in generalizing many of my findings. I had the acts, events of harmony and dissent recorded, yet many of my field categories resembled a disconnected mess. My data would take the appearance of specific situations where the relationship between relevancy and the purpose of my investigation became meaningless. I was still, to a large degree, a Madrona mover. I did not want to dehumanize the furniture movers. In fact, I could not abstract one iota. Yet, the questions that were to be answered from the counter-tendencies of status equality. and status differentiation would have to be abstracted to some level. I had to cool off for objectivity and in turn find those connections that were lacking at that time.

However, I doubt whether the cooling-off process is ever completed when using the participant observation method to its fullest capacity. The experiences that I had with these men will stay with me for the rest of my adult life. To gain a better understanding of a few experiences that a participant observer is faced with, refer to Appendix B. 


\section{CHAPTER III}

MADRONA TRANSFER \& STORAGE, INC.: DURING THE PERIOD OF OBSERVATION

\section{The Company and Its Operations}

Madrona Transfer \& Storage, Inc. is located in the Northwest industrial section of Portland. The company's livelihood is based on three different, but related, operations: 1) storage consists of storing customers' furniture, business machines, or wholesale goods for a specified period of time; 2) long-distance hauling (furniture or equipment being shipped out of the state that the hauler is contracted for) is on a contract basis with Repo Van Lines, and Madrona owns and operates three complete units (tractors and trailers), and leases out three trailers to individuals who own and operate their own tractors (lease-operator owned); and 3) the local move consists of any move that is billed through Madrona rather than Repo Van Lines, which usually means Oregon-based moves. The majority of these latter moves take place in Portland. of the above three types of operations, this thesis is directly related to the 'local move.' Hence, there will be a more in-depth description of the local move.

At Madrona the local move was broken up into four different types of jobs: household, office, machine, and piano. An additional type of move will also be mentioned: the sea-van move. The sea-van move is billed through Repo Van Lines; however, it will be considered local because the usual participants in this move are members of Madrona's work- 
ing group. Following is a brief description of each:

Local Household. A household move consists of a minimum of two men, driver and helper. Generally, the household move would take four hours. It is not unusual, however, for one to run into days rather than hours. This type of job is oriented toward the safe loading, transporting and dropping off of the customer's furniture. Every piece of furniture, no matter how decayed it might appear, is handled in a very delicate fashion. This kind of move is mentally and physically tiring.

Office Moves. Usually, an office move consists of six to eighteen men, which in turn will make up two, three or four teams. One team loads at the pickup point, one team unloads at the drop point and yet another team is injected somewhere, depending on the length and difficulty of the route the office furniture is carried. There is no consistent pattern between number of men used on an office move. In fact, the only thing that remained consistent is the type of furniture which usually remained the same from office move to office move. Organizing for speed and efficiency is emphatically emphasized in this type of job. Essentially, time is a priority over damage. Loading consists of floating (no stacking, one level and tieing off) the furniture into the trailer vans. The long hours (anywhere from eight to twenty-four at one time, to a week of long hours), the weight of the furniture (moderate to heavy), and the route (long distance, narrow passages, and/or stairs) make this type of job physically punishing and dangerous.

Heavy Moves. Here, a convenient category was manufactured to combine two very similar types of jobs--piano and machine. Both are similar 
by way of working those types of jobs. Both are usually a one-item move, but are heavy, fragile, and cost per item is extremely high. Pianos are from player, upright, to grand, and the machines are usually IBM computors, sorters, key punch, and automatic filing systems. Again, number of men would vary with the size of the machine, and routes to and from the truck. The route is important, for it i.s during the movement of a piano or machine that damage is most likely to occur. Gentleness is emphasized. These moves can be physically excrutjating, and are dangerous to life and limb.

Sea-Van. The sea-van usually consists of two men. Sea-vans are large, well constructed, wood crates that hold up to two rooms of furniture. They are used for the explicit purpose of moving furniture over-seas. The usual customers are servicemen and payment is made by the government. This kind of job is similar to the household move in a number of ways; more important, though, there are some significant differences. The container space is maximized when loading, the furniture is broken down (if possible) and wrapped in paper, paper cardboard, and/or packed in cartons. The emphasis is placed on precision loading; no holes; and packed as tight as possible. Most of the workers agree that loading sea-vans is a slow, painstakingly meticulous, but interesting, job; unloading sea-vans is thought of as slow, painstaking (unwrapping, putting together furniture, etc.) and boring.

In relation to company operations, the local moves (office move and household), as can be seen by the description of the types of jobs, is characterized by teamwork. The other two operations, storage and longdistance hauling, also encourage teamwork but not to the extent that the 
local moye does. Storage is basically warehouse work, which the Madrona workers feel is degrading to their status as furniture movers. They despise it because it is boring and monotonous work and it is work that is not related to the trade of furniture moving. Long-distance hauling does not really concern the Madrona worker; it is usually an operation that is separate and an entirely different group of men are involved in this operation. In fact, if a Madrona worker (usually a helper) goes out with a company driver or a lease operator, he becomes a financial responsibility to the driver, rather than the management at Madrona. In so many words, he literally is working for the driver and, therefore, is responsible only to his immediate boss--the driver. These are the company operations at Madrona. The one in particular that is of interest in this paper is the local move. For it is the local move where acts, actors, professional status, audience, and teamwork take on a meaningful dimension with this work group.

\section{Family as Management}

No matter how hard one may try, if observer or worker, it is impossible to neglect the superordinate. The superordinate is, of course, management. The management at Madrona Transfer \& Storage, Inc. is a family. The organization is family owned and run by the Madrona family. Each member holds a position at the managerial level, which has its own special area of responsibility. These positions are not vertically laid out, but they are seen by the Madronas as being horizontally related, each position being equally important in the maintenance and functioning of the company. The general rule at this level is that one's position and its related areas of responsibility are that of the immediate holders, 
and no one else, unless the other is asked.

However, during this investigation, Madrona Company was undergoing a moderate expansion in the direction of building up the number of leaseoperators for long-distance hauling. Also, at this time there was an unusual amount of intra-family dissension that was instigated more by personal problems than by business problems. Whatever these reasons were, in part, what caused a continual shifting and reorganization of positions and.related responsibilities which could, easily, in turn, influence more dissension by not knowing exactly what one's areas of responsibility was. It is probably safe to say that the dissension at the managerial level did influence many of the things that happened at the working level; however, at this time it is impossible to say how much. Management will be discussed more in terms of an unawareness, on their part, of particularly important professional acts and how, in turn, this awareness led to mistakes and eventually moments of dissent. To go beyond this immediate and overt relationship would be nothing but conjecture.

Outside of the organizational lines of communication informal communication between management and worker was common. Informal communication may have prevented and solved many of the problems that could have led to a complete disengagement between management and worker in the form of a strike (which will be discussed in the Appendix). The workers' face-to-face talks with different family members may have established legitimate communication lines for the issuance of grievances. This in turn may have at least held both Madrona management and workers together in a shaky relationship. However, this very important relationship is sadly neglected in the remainder of this text except for a brief 
description of certain related events in Apendix B.

Formaliy, the organizational chart looked something like the one

below. However, the chart may not be totally accurate at the managerial

level because of the above-mentioned shifting and changing of positions and areas of responsibilities.

Figure 2: Formal Organizational Chart of Positions

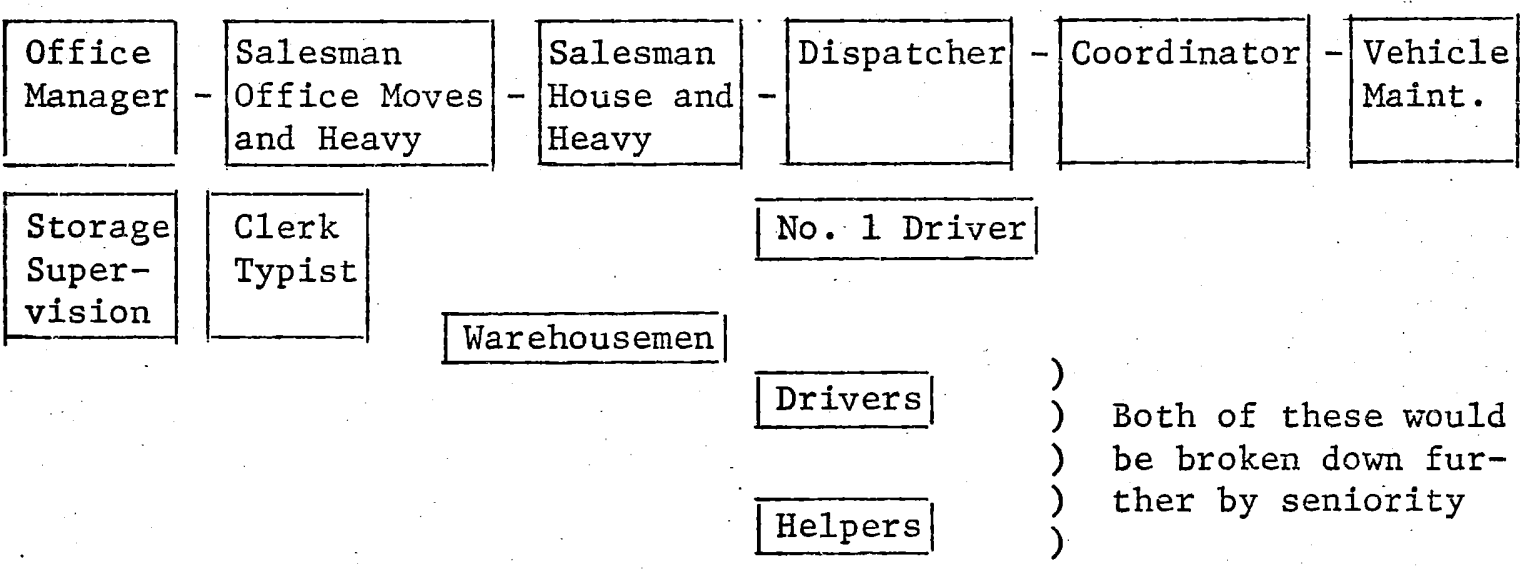

Figure 2 literally leads into the next discussion on the Madrona worker.

\section{The Madrona Worker}

At the working level of Madrona Transfer \& Storage, Inc., there are three positions structurally related to the operation of local moves, and one position that is unrelated--warehouseman. The three positions are the number one driver position, the rest of the drivers, and the helpers. Looking at Figure 2, each has a particular range of responsibilities that decreases from top to bottom. Each position and related responsibilities is described below.

No. 1 Driver. The number one driver is considered a working foreman. 
The fulfillment or leadership responsibilities of this position are highlighted in office moves. In this type of job he is directly under management in the issuance of orders. In other words, it is in this type of job where the No. 1 driver is actually an overseer.

His other responsibilities include: reporting any truck damage (he inspects the trucks every night), making sure trucks are locked up each evening, equipment is put away in appropriate places, and the back of each truck is clean and neat (consists of clean floor, pads stacked neatly, hand truck and refer truck tied up, etc.). If damage is found, the truck is unlocked or a messy back end. is found, he is to report the truck and the driver who had it 1ast. There is no fine if he happens to neglect those latter responsibilities, but he can receive a verbal reprimand by the management and if it continues, he may be fired, or removed. For these added responsibilities he earns $\$ 4.05$ per hour.

Because of the lack of office moves during the period of observation, the No. 1 driver was usually considered just another driver or more appropriately, a 'good furniture mover.' In other words, his duties as a leader were never consistently tested, because of the lack of activity that would have tested them.

The Drivers. Including the No. 1 driver, there are four local drivers. These drivers are formally positioned by seniority: seniority being based on length of time a particular person has worked for Madrona. Even with union seniority crosscutting Madrona seniority, the hierarchy of drivers remains constant. The formal duties of the driver are that he directs the helper(s) on any type of move. Seniority or the ranking of a driver is also related to the kinds of jobs he will be assigned to during the day. The high seniority driver will be assigned the heavy moves, and 
lower seniority drivers will be assigned household moves. In a manner of speaking, because of the frequency of assignments, they become specialists in types of jobs (which in a later discussion on harmony and dissent may explain in part their specialty in acts).

The drivers' ranking is also important in relation to overtime and slack time. Whenever possible, seniority is given a choice on overtime work (union regulations) and seniority is also given priority during a slack time. For instance, during slack time the No. 4 driver will be hauling feight, which is thought of as degrading to the worker. However, even though seniority appears important in relation to 'status,' it becomes less important with the discussion on the next group of men--the helpers.

The driver's responsibilities are concerned with his immediate job. He is morally responsible for damaged furniture (usually insurance will pay for it), and property that may be damaged by the truck he is driving. He is responsible for the time the move takes, and for charging the proper rates and for collecting the bill. If he does not accomplish the charging and collecting, especially if he undercharges, he may be financially responsible, depending on management's mood. He is also responsible for the neatness of the cab and the back end. Most of these responsibilities are moral rather than financial and a verbal reprimand is the usual method of letting a driver know that he is slipping. If the driver continues to slip, he will be laid off (a nice way of firing someone). For these responsibilities the driver earns $\$ 3.95$ per hour.

The Helper. According to the organizational chart, the helper is situated in a position of lower status. He is ranked below the drivers 
as a group, which means if a driver were to conform to this chart, he would be in charge of any of the helpers. However, the helpers are. ranked by seniority the same way the drivers are. An inconsequential pattern is that teams of both high ranking drivers and helpers would be picked for a particular job. A consequential pattern is that more often than not teams are randomly selected without any purpose of intention; matching up drivers and helpers in relation to seniorities was not important unless there were new men that had to be teamed up with the more experienced workers. The random selection of drivers and helpers points out that drivers and helpers did not form cliques where it might be called a working group of 'twos' rather than what it actually is--a working group. The relationships between drivers and helpers were more diffuse than explicit.

Generally, the helper is subordinate to the driver. The driver is in charge of the job and it is up to him to direct the helper in what pieces of furniture he wants for loading. The helper has no responsibilities as designated by the organization; his responsibilities are set by the driver. According to management, the helper is not at blame if the move turns out to be bad; customer dissatisfaction is the driver's responsibility. Unless the helper is blatantly bad, the driver has no way off the hook. However, the occurrence of blaming a helper was minimal and usually the driver would be blamed. (This was not a frequent occurrence, for the customer would usually not call the management.)

The above illuminates a sort of subtle power dimension that the helper's position may contain. Because all of the responsibility of a gaod move is placed on the driver, the helper can do subtle itttle things that can hinder a job's rhythm and movement. For instance, it is 
not too uncommon for a 'nasty' driver to find himself being smothered in furniture as he stumbles and trips in the back of his truck attempting to load. The rhythm of the move is sporadic and movement may come to a complete halt. From the customer's viewpoint it looks as though the driver is at fault for the helper is working extremely fast and besides he is sweating, and "isn't that what it's all about?" Indeed, the helper can make things miserable for the driver and in a manner that will help the driver learn or remember the 'professional acts.' The helper is an indispensible member of the team and for this he earns $\$ 3.90$ per hour.

\section{The Madrona Men: A Profile}

Most of the discussion has been spent on describing the structural characteristics of Madrona Transfer \& Storage. The operations, the moving jobs, the management, and the workers have been described in relation to the formal characteristics of Madrona. The roles of driver and helper were presented to show certain overt responsibilities and subtle powers. The following discussion will center on each of the eight men that make up the Madrona work group. Each man will be discussed in relation to years at Madrona, approximate age, position, and personal makeup as related to the work group. All information pertains to the time of my participant observation; and just the first name of each worker will be used.

Einer* is twenty-six years old. He is in the number one driver position at Madrona. Einer has been working at Madrona for approximately seven years. He is not a member of the Madrona family, but is a cousin

*These are ficticious names. 
of Joe Zenner, who is married to one of the Madrona women and is himself in a managerial position.

Einer is considered by his fellow workers as an excellent heavy mover. His specialty is the moving of IBM's and pianos. He is also considered quite good in office moves. However, probably due to his lack of experience, he is not considered a strong leader in office moves. As compared to the former number one driver, Don (who was foreman during my first working experience at Madrona in the summer of 1968), Einer does not have the fortitude to deal with certain members of the Madrona family during an office move. Also, Einer would relate to the management certain grievances and complaints of the workers, but he did not have the forcefulness that is sometimes needed to show that they are important. This may be due to his connection with the family, and the added distraction of marital problems during the summer of my participation.

Einer gets along quite well with the other members of the work group: He does hold respect in the smaller moves (number of men) and deals with customers in a friendly manner. However, he does have a tendency to play when backstage (i.e., truck cab, warehouse, van, delivering freight, etc.). This is sometimes distracting in relation to other workers' attempts to enact professionally, and consequently may have something to do with his ineffectiveness in relation to certain leadership responsibilities.

Jessie is approximately thirty-four years old. He is the number one helper and has been working at Madrona for around ten years. He was born and raised in New Orleans, moved to Portland, and began working at Madrona. He is married and has four children. Jessie is considered an excellent all-around helper. This means 
that he can do any type of move, and do anything that is demanded of him during the move. He is a quiet person who has gained respect through being good at his job and speaking only when something must be said. He is a very personable person who behaves in a very consistent manner, even with a hangover. Jessie, in his quiet way, is a leader. During sone of the more catastrophic office moves, Jessie. would be looked at by other work group members for leadership in bringing them through a crisis. Towards the end of the summer, Jessie was elected to the position of shop steward.

Bob is number two driver and is approximately twenty-eight years old. He has been working for Madrona for approximately five years. Prior to working for Madrona he worked at another local moving company. He is married, has one child, and is a 'car nut.'

Bob is considered to be an excellent household mover, He is good with customers (some workers, however, did not think so) and is very damage conscious, fast, and can load local household moves in a fast and efficient manner. However, Bob is not well liked by some members. of the work group. Ray and Bob have had a running battle for approximately two years. Ray does not like Bob because he is 'too bossy' and talks too much about his financial problems. Bob does not necessarily like or dislike Ray except when they are on a move together and Ray begins to take out his hostilities by jamming the back of the truck with furniture. Bob and Jessie also had a running battle for a few months and again this was due to Bob's autocratic behavior while working on a job. However, during a lengthy discussion between Bob and management he was told that he should not play dictator to certain helpers. That talk had the result of toning down his bossiness from then on. This 
alleviated the hostllities between Jessie and Bob, but not between Ray and Bob, who are probably to this day battling each other.

From my view, one of the more humorous antagonisms that developed was between Bob and Jim. These two men considered themselves 'strong,' which indeed they were; however, this virtue of strength was carried to the point where they would perform feats of strength with other people's furniture (e.g., Bob would carry a color T.V. set by himself and Jim, in turn, would carry a good sized stereo, or both would carry as many cartons of books as they could). Needless to say, this was watched by their fellow workers with a great deal of delight (and who in turn labeled them before and after), and by the customer with a great deal of nervousness. It is apparent that Bob is the protagonist of the group and it could ba because he is not capable of 'giving advice' (one of the professional acts which will be discussed more fully in Chapter IV).

Ray's age is unknown; however, a very rough guess would place him in the neighborhood of forty years old. Ray is number two helper and is unmarried at this time. For most of his working life he has been involved in the transportation area. At one time he owned his own tractor and hauled anything available. However, due to certain circumstances, and a few too many 'bennys,' he lost his license to drive trucks.

Ray is considered an excellent helper. This 'excellence,' though, is with one qualification: "when he wants to be, he is excellent." of all the men that belong to the Madrona work group, Ray by far has the most erratic behavior. He can be hilariously humorous, or be deadly sinister. He can treat the customer with a great amount of respect or he can treat them like 'dirt.' With his fellow workers he can be the most 
friendly of friendly people, or he can become fanatically hateful. These moods not only change from day to day, but they can change from moment to moment especially with those that are on his 'dislike list.' With those that he likes, he usually stays very personable and friendly. When he is personable, and when 'he wants to be,' he is looked on as one of the working leaders.

Maybe because of his erratic behavior, he is not initially confronted by very many fellow workers. Ray usually initiates a confrontation. During my participation there was only one work group member that initiated a verbal war with Ray and that was Jim. This conflict started over a pool game and later was carried into the work situation. It was a conflict between two hard noses that was a real threat to the group; it was blatant, overt, and ugly. This is the only conflict between any members of this work group that was resolved by the work group members with due speed. This conflict gave Bob a slight rest in his traditional battle with Ray.

Ron is the number three driver. He is around thirty years old and is going through marriage quandrums. He has been working for Madrona for approximately six years. However, about four to five of those years he has been driving long hauls as a company driver. He came off the road to patch up his marital problems and hence began working as a local mover.

Ron is considered a fine long -distance mover and an excellent driver of tractor-trailer combinations. However, as yet he is considered only average on local moves. There are two apparent reasons for this. One is that the loading style between long distance and short local moves is different. The difference is reflected in the time spent on 
the two kinds of moves. On a local move Ron takes too much time to load; this at times destroys the coordination between him and his helper. Secondly, certain acts, such as advice, are not needed on the road; and, as yet, he has not been socialized to the point where he is aware of the significance of such an act in local moves.

Ron is very friendly and is well liked by most of the work group members. He considers himself a woman's man and blatantly flirts with any two-legged female. He is from Boston and has a very noticeable Bostonian accent, which is the brunt of many jokes and mimicry. He also considers himself quite a cartoonist, and on moving jobs one usually will catch a glimpse of very funny looking mice drawn on a box. In many ways, he may be considered an expressive leader for he does relieve tension, especially in office moves. However, Ron does have 'bad days' and becomes quite withdrawn and is easily hurt by remarks made to him.

Jim is number three helper and is around twenty-four years old. He is married and has been working for Madrona for a year (although he had worked for Madrona about three years earlier). Before coming to Portland he had worked in Alaska for a moving company and in that respect is quite experienced in furniture moving.

Even though experienced, Jim is not considered an excellent helper. He is a helper who will work, but he does not bring any color into the job: color being all those ingredients that define a job as an avocation rather than 'work.' While working, Jim has a certain depressing air about himself and the type of work that he is doing. The other workers considered him grouchy and depressing, and it was apparent that these feelings were released by degrading the other team members. This made the job from beginning to end a miserable experience. However, at the 
completion of the job and once in the truck cab, he became extremely funny and transformed into a very warm person. At times it took the other team members a rather long time to reciprocate Jin's friendly overtures.

Jim's 'mouth' was a constant hassle; he apparently liked to 'rank' other people, customers, workers, and management--it didn't really matter. Maybe the clash between Ray and Jim was inevjtable.

John is number four driver and is new to the occupation of furniture moving. He is married and is around twenty-five years old, even though he looks like he is in his early thirties.

John is considered by the other movers as having potential to be an excellent furniture mover. He has the qualities of 'getting along with people,' of 'being damage conscious,' of 'getting along with his helper,' and of 'being strong.' However, even though John was serious, humorous, and gave advice (as versus orders), he still had problems with the most important act of al1--coordination. The other acts apparently came quite naturally to him (unlike Bob, who had to be told that "advice is better than orders"). John, though, toward the end of the summer was learning that you just don't pick up a divan and walk without any concern for your team member on the other end. He was becoming more conscious of the act of coordination, the overt technicalities and certain subtle acts.

Bill vacillates between employment and unemployment at Madrona Transfer \& Storage. When employed, he is placed into the number two driver position. He is approximataly fifty years old and has been working in furniture moving for most of his working life.

When Bill is off the bottle, he is considered a mover par excellence. For most of his career he has been working line-haul. Even though he can 
do every phase of moving with excellence, his supremacy lies with loading. Because of a drinking problem, Bill is sporadically on and off the road. When off the road, he works local moves; and, if he can't get off the bottle when working local moves, he is temporarily laid off until he dries out. Even though certain jealousies arise because of management's blatant leniency toward Bill's sporadic binges, the men at Madrona still respect Bill as both a person and a mover.

Bob, Ron, Ray and Jessie have indicated that their knowledge of furniture moving is to a great part due to Bill. A11 of them indicated at one time that Bill is the person to learn from. They added that if you work hard for Bill, he will go out of his way to help and teach you the skills and techniques of furniture moving. When working with hims I never found him brash or arrogant about his skills. He was always willing to share his ideas with anyone who showed an interest. When working with a helper, he never gave direct orders, unless absolutely necessary (e.g., if a large piece of equipment was beginning to slip on a staircase, then he would give direct orders). When loading, he would usually bring the helper into the dicision-making process by issuing advice or asking for suggestions. The one professional act Bill lacked was humor, and maybe he didn't have too many things to be humorous about (his drinking problems, his wife, and others). However, what he lacked in humor he made up in the other three acts of coordination, seriousness and advice. Maybe even more important than the acts, Bill was an object lesson of a skilled person who simultaneously acted in a humble, sincere and honest manner. 
Furniture Moving:

A Degree of Technique and Skill in Loading and Hauling

As the discussion moves into Chapter IV and the professional acts, very little will be said about the actual skill needed on the technical side of furniture moving. On the technical side, the two general categories of loading and hauling will be discussed.

Loading furniture into a van takes a great deal of skill and experience. The objective of loading is to take as many pieces of furniture as possible and stack it into a "tier." A tier runs from one side of the van to the other and its height is determined by the van's ceiling. An excellent loader will compress as much furniture as possible into the smallest unit of space. In doing so the loader is making a "tight 1oad" that will not result in damage while transporting the load of furniture. On a line-haul this is done for two reasons: to prevent damage and maximize weight. On a local move it is done for the reason of preventing damage.

In determining the extent of a loading job, the loader will roam through the household and acquire a picture of how and in what order he will load the furniture. For example, he will make a decision on the height of his tiers. When low tiers are decided on, it is called "floating"; when high tiers are decided on, it is called "line loading," even during a local move. He also must make sure that the weight of the furniture is evenly distributed throughout the van so that he minimizes the dangers of a truck being side heavy and tipping over.

He also must make decisions on the order in which the furniture is to be loaded. For example, to make sure that the tiers do not tip toward 
the rear of the truck, he may want to load the mattresses and heavy appliances as props at the end. Also, china closets are very delicate pieces of furniture and a good proportion of a van's wall must be used as a brace for the closet. In loading, he must make sure that nothing awkwardly loose, with legs, or heavy, is loaded next to the closet or any other fragile furniture. For reasons of space, convenience, and/or lack of time he may not be able to save heavy pieces until last. He must then determine when to "slope" his tiers so that he doesn't run out of room in the van. The slope technique also prevents tiers from falling.

In loading a tier, there are three general levels: the 'base,' the 'middle,' and the 'topping.' The base consists of a flat-topped heavy to moderately heavy piece of furniture. For example, drawers, washers, dryers, cabinet stereos, cabinet T.V.'s, large cartons, wardrobe cartons, etc., make excellent bases. The middle consists of moderate to light pieces of furniture. Chairs, small cabinets, portable T.V.'s, middle-sized cartons, etc., are quite popular at the middle level. The topping, of course, is the residual level where all the light, awkward, and small pieces of furniture are placed. The most popular items at this level are lampshades, toys that can't be boxed, garden tools, T.V. antennas, etc. From top to bottom, pillows and cushions are used as 'tighteners' to apply horizontal pressure between pieces of furniture.

Hauling furniture from its origin to the van is the other technical category involved in furniture moving. The objective of hauling is to get a piece of furniture from its point or origin to its destination, from house to van or vice versa, in the shortest period of time without damage occurring to either the piece itself or the interior of the house. 
Unlike loading, hauling runs from a routine pattern to, at times, innovations. Routine-wise hauling is essentially picking up items and carrying them through to the truck, setting them down within reach of the loader and returning for another item. The only things a hauler must worry about during a routine phase is not to damage walls or fall off the ramp by falling asleep.

Innovations arise when the items increase in size and weight and two men must get them out of a house. The challenges begin with interiors like curved stairways, low overheads, narrow doorways, narrow hallways with a side door that leads in the direction that the movers want to go, and long distances between origin and the back of the van. For example, an interesting and innovative technique in getting a nine foot daveno through an eight foot high side door in a narrow hallway is to 'curl' it through. The daveno is tilted to where the end next to the door is lower than the opposite end; the daveno is at an angle to the door itself. The lower end is moved through the door; simultaneously the movers are curling it so that it may fit at the angle it is entering. Also while 'curling' the lower end is slowly raised and eventually when about one-quarter is through the door, the back end will be lower than the front. From this basic design, innovations occur. in 'curling' so that most doors and hallways can be coped with.

Hauling of IBM machines and pianos especially take a great deal of technique and skill. For example, upright, grand, and player pianos come in all sizes and weights. Each type is dealt with in a different manner. The grand is completely stripped of legs and pedals. This is done to balance out its weight and to prevent damage. The weight of a grand is distributed evenly when stripped and tipped sideways on a piano dolly. 
Even with this equal distribution of weight, the balance point is so critical that a slight tilt may send it crashing down. Both IBM's and pianos are heavily padded while hauling them to prevent damage to both the piece and the walls and doorframes that get in the way. While hauling one of the valuable monsters, the team will usually take it very slowly and handle the piece like it was a giant baby.

This has been a brief description of the technical nature of furniture moving. This section was presented to show the reader that skill and technique are important in furniture moving, since little will be mentioned about technique from here on. Even though Chapter IV concentrates on behavioral patterns, it is important to realize that technique and the professional acts supplement each other.

\section{The Customer}

When discussing moving men, it is impossible to neglect the customer. The customer is an important part of Madrona Transfer \& Storage, Inc. The customer that is important in this thesis is the one that the worker meets on local moves. The customer that the Madrona worker meets runs from the very poor (Portland Development Commission clients) to the very rich; from the deadpan to the exciting; and to the ugly depressing and to the very funny. In total this means that the local move is a job that contains a certain amount of surprise with the kind of customers the worker will be performing for. There are two general types of customers: the office worker and the household customer.

The office worker is found in office moves and machinery moves. He is detached and usually leaves the Madrona workers to do their own 
jobs. He usually directs the workers to the piece that is to be moved and may suggest an appropriate route. From then on the movers are on their own, which is a priority preference for them.

The office worker who attempts to act overtly superior is suddenly confronted with a rapping dialogue that completely shuts him out from further interaction with the movers; or else orders are met with a long drawn out, "suuure!" The office worker is not handled with a great deal of care; in fact, putting them on is a kind of sport, and if the workers are found out, it is not really serious. However, when the actual moving of the machine or equipment begins, the workers become professional. This concern is directed toward the piece for it is usually worth a great deal of money and is extremely heavy. Not too often, though, the workers have a fairly easy piece to move, but the put-on continues: they flirt, they rap, and they make it appear that this is the roughest job that they have ever had.

The household customer is different. This customer is not detached and usually does not leave the workers alone. In many cases, the furniture may be worth a great deal of money, but more important, there is an apparent customer sentiment in relation to their furniture. Because of the customer's engagement, their moods become highlighted in a household move. With this kind of customer, the Madrona worker will work at satisfying their demands--up to a point. If the demands take the form of giving orders and directing the move, the Madrona team will attempt to establish their superiority. The Madrona team will not put-on, but instead will become highly professional in their approach. Everything they do is geared toward the movement of the furniture in a careful, 
well coordinated, serious fashion. They may talk about other things when the customer is out of earshot (usually, the back of the truck), but when the customer is present, the team will pull everything they can out of the professional package to establish their superiority and satisfy the customer at the same time.

Besides the interplay between workers, there is also an interplay between them and the customer. They want the customer to respect them and grant them status. To accomplish this, they must relax the customer. and pull him into the drama of professional furniture moving. However, as the discussion in Chapter IV will show, this is not an easy task, nor is it an easy task for the workers themselves to stay in harmony. 


\section{Introduction: Reading Chapter IV}

This chapter is segmented into three.sections. Each section is an attempt to discuss an aspect of the relationship between the contradictions of status equality and status differentiation with harmony and dissension. Section I deals with status equality and status differentation relationship with harmony. Section II is a short discussion on the worker's ambivalence in choosing alternative lines of action that will result in an experience of status equality and/or status differentiation. The result, though, is dependent upon the reciprocal action of the recipient. This section attempts to establish a transitory stage into Section III, which is solely concerned with dissension and its relationship with the contradictions of status equality and status differentiation.

In attempting to illuminate the connection between the abstract notions of status equality and status differentiation and the related peculiarities of the Madrona men's behavior while working, a level of discussion was decided upon that approximates explanation rather than detailed description. However, during the discussion a few specific incidents were injected so that one does not lose touch of the cast--the members of the Madrona work group. If the reader desires more detail, Appendix $A$ has been constructed for that explicit purpose. Appendix A 
is essentially edited field notes and footnotes to Chapter IV. They are basically the field notes that directly are related to the behavioral aspect of the Madrona workers. Any statement or word that is quoted in both Chapter IV and Appendix A is directly taken out of the original. field notes.

\section{SECTION I}

\section{HARMONY: STATUS EQUALITY AND STATUS DIFFERENTIATION}

The Madrona crew constantly referred to themselves as professionals--professionals in the sense that moving furniture was an artistic trade. During my involvement a11 of the Madrona workers stated that each job, no matter how similar, always consisted of differences that needed to be reckoned with in an innovative fashion, a fashion that closely parallels artistic ability. They continuously used the artistic, or the innovative nature of furniture moving, as a professional reference. Even before my observations, there was a period where the management had attempted to inject the label 'furniture engineers.' This did not get off the ground with the workers who, in fact, still continue to laugh about it when it is mentioned. Hypothetically, if management were to label the workers with any name that did not truly depict the special thing about furniture moving, the workers would also laugh that into the ground. ${ }^{1} *$

It sounds as though we have a paradox forming. If the workers at Madrona believe themselves to be involved in an artistic profession, then why don't they appreciate a label that highlights such a virtue? If we

*Quoted remarks are taken directiy from the men at Madrona. 
investigate further, we will find that this paradox is well grounded. For instance, with regard to the Madrona workers, there was a subtle distinction between working toward something as opposed to working under something. To work under a title that defines them as artists or engineers would predispose them to a position that is defined by outgroup members as illegitimate, so illegitimate that they would be stigmatized as clowns rather than professional tradesmen. ${ }^{2}$

Just as important is the fact that the Madrona workers' conception of 'artist' or 'engineer' denotes a different meaning than what they mean when referring to themselves as artistic tradesmen. The workers are well aware of phony headings that are applied to certain low status occupations; they too laugh at the occupational title of "sanitary engineer," and they do not want the same laughter befalling the occupation of furniture mover. To the Madrona workers, 'furniture mover' is label enough and to decorate it with 'fancy words' is simply considered 'phony.' They do not want to work under a pre-defined heading for that would pre-dispose the workers to act in ways that are not entirely consistent with their own notions of appropriate behavior. To work toward their definition of professional acts, they accomplish two important functions:

1. The Madrona workers believe that most customers have a low opinion of their profession, and the acts add a touch of drama to a move' which in turn highlights the technique and skill of furniture moving. ${ }^{3}$

2. Simultaneously, the Madrona workers are engaged in acts toward a group-defined goal which helps them near status equality with each other. 


\section{The Professional Acts}

A professional act is behavior that is consistently acted out in front of an audience and has been proven successful in attaining a desired level of group status. The Madrona crew considered four acts as being highly important in attaining a level of professional recognition. These acts, coordination, seriousness, advice and humor, will be 1isted below with their definitions and origins.

Coordination is by far the most important act since every moving job at Madrona entails teamwork of two or more men, depending on the type of the move. There are four apparent reasons why coordination is important: 1) some pieces of furniture are simply too large for one man to push or carry; 2) coordination between individual workers and synchronization of movement lessens the chance of physical injury; 3) related to this latter statement, coordination lessens the expenditure of energy; and 4) emphasizing of coordination looks good to an audience. 4

Coordination transcends every level of moving from the most observable, where two men are synchronizing their pace, rhythm, and motions to each other, to the more unobservable, where a large number of men are attempting to coordinate their pace and speed to the degree where "jam up" will be lessened and they will not have to work at an energy expending, sporadic pace.

The origin of coordination is deeply rooted at both the managerial level and the worker level. It is constantly mentioned by all involved parties as being important and is so highly integrated that it is probably safe to assume that the origin is intrinsically tied to the nature of the work itself. 
To act serious is to appear concerned about the task at hand. The impression during $a$ job is that seriousness is influenced by two major factors: (1) physical injury and the "damaged furniture taboo"; and (2) customer sentiments tied to pieces of furniture. The first factor orients itself toward both management and worker levels. The threat of physical injury is always apparent in furniture moving. Injury in any form can mean at the least discomfort, and at the most it can mean being crippled for life, or even death. This act of seriousness is invariably upheld among the workers; as the furniture or equipment increases in weight, so does the sincerity of the act.

The first factor also concerns itself with damage. Damage not only costs money, but of equal importance is the fact that it hurts the professional standard that both management and worker desire. Damage to furniture, walls, floors, overhead, glass, etc., is all considered taboo. "Scratches," "gouges," "dents," "cracks" and "scuff marks" are the most common occurrences of damage. In a majority of the observed cases this type of damage would either go unnoticed by the customer or the customer would simply regard such damage as unimportant. Whatever the outcome, in comparing the actual damage to the damage done to the culprit's ego, the latter far outweighs the former.

The above statement conveniently leads us into the second area of seriousness--customer sentiment. It becomes quite apparent when moving furniture that many of the pieces have little cost value; however, to the customer there may be a high degree of sentimental attachment to these same pieces. Here, seriousness takes on a different quality. The serious act is directed toward the customer rather than the piece of furniture. The handling of a small, fragile lamp with the gentleness that one would 
use to handle a newborn baby is purely for the customer's benefit. This type of serious act assures the customer that the Madrona worker is a concerned, serious professional. This, in turn, relaxes the customer, reduces the strain between all of the involved parties and helps in the promotion of the other professional acts.

The origin of the serious act is difficult to pinpoint. Unlike coordination, however, it does not appear to be inherent in the work of furniture moving in and of itself. It is an act that has a much broader scope than coordination: an act that emerges from the specifics of physical injury and damage, as well as from the ambiguity of 'customer sentiment.' More accurately, the origin of the serious act appears to emerge from a broader base-the interplay between nature of work, management, worker, and customer.

The act of humor generally takes on the appearance of a tensionrelease mechanism. In any type of move the Madrona workers will promote. a dialogue of 'rapping humor.' This takes the form of short, sporadic quips that ideally and spontaneously fit into the mood of the move. "Hurry," "how come," suuure," "what a dummy," "suuure, he can do it," are a few examples of this mode of humor. This type of humor is usually carried on between workers and either supplements or supplants the act of seriousness. If a move is going well and the serious act has been successful in alleviating the customer's seeming distrust of the workers, the humor act is presented in full view of the customer(s). In other words, the workers are attempting to supplement the serious act; an attempt is being made by the workers to change the situation from one of a distinct worker-client role relationship to one nearing a friendly relationship. The Madrona workers by the very fact of acting serious are fitting into. 
a partial role that is not only defined by them, but is also pre-defined by management and customer; hence, definite status distinctions would be the result. With the humor act, however, they are coloring this role with unexpected human qualities that have the propensity to make role distinctions somewhat ambiguous. 5

If the serious act appears to be failing in reducing customer fears, the act of humor has the capacity to supplant the serious act. There are all kinds of personalities that a Madrona worker must confront and the one that does not loosen up under the serious act is considered a "cold fish." In fact, the serious act has a tendency to intensify the "coldness" of this type of customer. The act of humor is then brought in to supplant or offset the failure of the serious act. However, there is a slight change or altercation of the act's direction. Before, the act of humor sort of rolled out of and perpetuated a friendly mood; now it is primarily for the benefit of the workers who have failed to make the situation more comfortable. Before, there was a high propensity for the customer to be drawn into the drama of moving; now the workers are separating this tension-producing audience and performing for each other. No matter what the drama unfolds, however, the act of humor is a means of nearing. status equality. 6

The origin of the act of humor is completely informal. Out of the informal relations that have developed, a special brand of humor has emerged to help erase status distinctions between the relationships of worker-client and worker-worker. The management is inconsistent in their interpretations of this mode of humor. At one moment management may interpret this humor as the workers mean it to be interpreted--a means to arrest tension and to establish a friendly mood; at another moment, 
however, management may simply interpret it as 'play.' (Play is a taboo area for the workers, for it opposes serfousness.) Whatever management or even customer interpretation may be, humor remains an important force toward worker performance.

The last act is that of giving advice as opposed to giving orders. This act, as humor, is also worker oriented. The combined acts of giving advice and humor are recognized as containing those particular ingredients that are helpful in nearing status equality. As mentioned before, the Madrona workers were under the imposition of a status distinction that had been set by management: the driver-helper dichotomy. When new drivers entered employment at Madrona, management toid them that they were in charge of the helper. The helper was portrayed by the management as someone who was basically "dumb and lazy," which in turn was interpreted by the incoming driver as someone that he must "constantly stay on top of." However, as a new driver begins to be indoctrinated into the work group, he soon learns that the helper is not basically 1azy. That certain helpers know more than he does about the profession of furniture moving. Last, but not least, the helper definitely does not like to take orders. If the driver is a slow learner and cannot comprehend these three relevant facts about his helpers, he begins to wonder about certain things, such as: why does his back hurt every night? why does the back of his truck fill up faster than he can load it? why is he working in the box car, unloading glassware, more and more? Both a new driver and a new helper learn the meaning of teamwork or they are subtly or very distinctly driven out.

The meaning of teamwork to the Madrona workers is equality: "no man is better than any other man," "everybody shits the same." Giving 
advice is essentially their weapon in fighting a cumbersome and degrading formal status system. In giving advice, both the driver and the helper are taking part in the stratagem of the move. In giving orders, there is only one participant--the driver. The helper is merely a conveyer belt transporting furniture on command. Giving advice, on the other hand, has the affect of bringing the helper into the arena of action where he is able to give out ideas and make decisions. At the end of the move both driver and helper will feel responsible if it is considered a 'good move.'

Advice, as humor, is also a product of the informal relations between the Madrona workers. It is important in the function of closing status distance between workers (especialiy as noted in the driverhelper dichotomy). The act of giving advice plays a major role in illuminating to both the audience and the workers the essence of furniture moving teamwork--equality and togetherness. 7

\section{The Acts: Highlighting Skill and Technique}

It becomes quite clear that these acts portray only one side of furniture moving; that side leans heavily toward a dramatic framework rather than a technical one. Technique is that side of furniture moving which is the most unexpendable, for it is the basic rules, tricks and know-how that each mover must learn before he can move furniture skillfully. Technique then becomes important for it does emphasize a quality both workers and audience look for--skill. Technique in furniture moving is highly visible and therefore the propensity to illuminate skill is also great. The crux of the matter, however, lies in the fact that technique as a singular factor of a profession does not necessarily lead 
to the recognition of skill. For example, there were a few times when one went to work feeling hung-up, hung-down, drug-out, and rung-out. If this poor soul teamed up with another who felt the same way, these two unfortunates would have a ghastly time of handling the repertoire of professional acts. In situations such as this the act of coordination would be the only one that would be pulled out of the professional package; as already mentioned, it is directly related to technique. When enacted in this kind of situation, coordination would be used for the explicit purpose of getting by rather than showing off. The remainder of the acts would not enter into this type of move for the simple reason that the workers did not have the energy to act them out. In this type of situation, being blasé describes the mood or emotional tones of the workers; this type of move was never considered either good or bad by the workers, but was just considered as one of the "Oh, Hum" jobs.

Even though technique existed to the point where no damage occurred and the move was completed in a reasonable length of time where both customer and management appeared satisfied, this move was still considered mediocre by the workers. Technique is an intrinsic part of the job; it neither subtracts nor adds to the workers' performance. The workers perceive technique as merely the mechanical way of moving furniture. It is the professional acts that add or subtract quality from the workers' performance.

So far, an attempt has been made to show how these acts contribute to group status; that is, how the workers attempt to enact these acts during a job and in turn how these acts lessen the strain among workers, and between workers and clients. By the nature of working together, or more precisely, working within the confines of the acts, the workers are 
simultaneously 'joining the group.' This joining is depicted by a shared consensus that particular acts are beneficial for a professional performance. These acts are beyond formal status distinctions--all must act them out. Noone is excluded when moving furniture, therefore rending these acts as equalizers; or more appropriately, they offer the worker a 'sense of community,' a feeling of status equality.

\section{The Moving Jobs: A Subtle Routine}

Refer to Figures 3 and 4 for the remainder of the discussion. These figures represent a highly routined household and office move. They were manufactured to help understand the process involved in a moving job. Remember, though, the routine that is emphasized by the figures is highly exaggerated.

When both driver and helper begin to work toward the professional acts, there is a sequence of stages that usually occurs that marks their placement when they are initiated, not that the stages are rigidly conformed to. More precisely, the stages are a part of a process that logically allows for the act's entrance into the situation. Though the stages appear quite apparent, in actuality it is quite a subtle routine that does represent a certain amount of expectations on the part of the workers to initiate the professional acts in a sequence that is subtly related to the stages of a moving job; that is, if the move is indeed going along in a routine fashion. However, there were few moving jobs that resemble a sequence of stages, one after the other. In many instances the stages would pile up on one another or even be reversed in some cases. 
Figure 3: Household Move by Stages with Appropriate Acts and Comments

\begin{abstract}
Coordination Seriousness
\end{abstract}

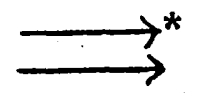

STAGE 1

STAGE 2

Backing truck up

\section{Greeting \\ customers}

Helper very seriously giving elaborate hand signals
Advice

STAGE 3

Driver picks up small items, goes to back of truck

Driver with involce greets customer with show rooms of furniture to be moved smile and asks him to
Both driver and helper converse about'easiness or difficulties involved--"Let's get some base"--both driver and helper go back to house or back to warehouse for next assignment Truck unloaded--
driver collecting
money

Figuring hourly rate-hope the customer does not lose sense of humor

Helper straightening up van

Stacking pads and sweeping out

\section{STAGE 4}

Begin loading

and hauling

Driver now in back of truck--helper attempting to set pace with driver's speed in loading, vice versa--estab1ish supremacy, will not take orders from humor thrown out customer

\section{STAGE 7}

Unload both driver and helper

\section{Some Humor STAGE $5^{* *}$ \\ Pace set-- \\ customer now partly relaxed \\ Driver and helper both loose and mov- ing--start joking back stage--helper making comment on furniture to cus- tomer. Little}

\section{STAGE 6}

Truck loaded-go to drop point

Customer allowed to tell movers where they want the furniture placed--the customer now beginning to be more involved--if he was relaxed before unDriver and helper talking about customer--some difficulties they might face at drop point-loading

\section{customer now relaxed}


FIgure 4: Offlce Move by Stages with Appropriate Acts and Comments

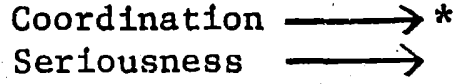

\section{STAGE 1}

Pulling tractor and trailors in

\section{STAGE 2}

Management there-begins giving orders

\section{Teams form to} accomplish specific tasks of trailer and line side doors with building doors--everybody unloads equipment

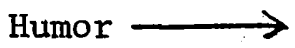

\section{STAGE 3}

Attempt to coordinate between team members

\section{Humor among} the workers only

Management may form

the teams before, or now, or the movers may form their own teams
STAGE 8

Some of the men are sent home; those that remain continue to put the items away

Humor is decreasing-tempers momentarily flare

\section{STAGE 4}

Attempt to coordinate between teams

Humor now may begin to be directed at office workers
Advice

STAGE 5

Coordinated rhythm between all involved-teams are established Advice is beginning to be given rather than orders
Go home or

to tavern

\section{STAGE 7}

The pick-up point is now empty. The team will now go to drop point and put furniture in appropriate place

Everybody is getting tired and is of giddy humor

\section{STAGE 6}

Floating items on trailor--when loaded they take off while another one takes its place

Another problem beginning at this point: the team that is loading must try to coordinate so jam-ups do not occur at one or both ends

*Arrows indicate that the men begin and attempt to follow through with the acts throughout the move. 
For example, there were times when the driver would be backing up, the helper directing him in, when the customer would come up and say something like, "I wish you wouldn't back up my driveway; you might go off the edge and destroy some of my flowers." It is difficult to smile in a situation like this when the driveway leads right up to the door and the street is some distance away. There is nothing worse than carrying piece after piece of furniture long distances from house to van. If something like this occurs, the driver would usually get out and both driver and helper would seriously talk about the chances of damage, increase in time and money when one is moving and carrying long distances.

Another incident that occurred was establishing the supremacy part of Stage 4 while unloading in Stage 7 . For example, everything may be working, the customer is relaxed and congenial, until he begins directing the unloading and placement of his furniture. He may become autocratic and impatient. Because of the functional aspect of letting the customer direct the moves, the workers may find it difficult to cope with this change in behavior. They may begin again to establish their supremacy by asking another member of the family. If the husband is at fault, they will go to the wife, or vice versa. If there is no other member available, they may simply slow down or, at worst, take pieces of furniture into the house and set it where they think it is appropriate. 


\section{Status Differentiation}

No one likes feeling constantly equal to everyone else. We all want to feel, or would like to feel, somewhat superior at moments. Maybe a better term than superior would be 'separate' or 'different.' Being 'separate' or 'different' connotes a lack of community, a lack of status and equality. Yet, this separateness that man desires is a basic human component of any group, including the men at Madrona. The men at Madrona were perceived at the same time as professional furniture movers and as separate and different human beings. The same acts that promote togetherness also have the flexibility to offer individuals innovation so that separating can at least be momentarily possible. The acts not only promote status equality in that they are shared by all the Madrona workers, but also because of the acts! flexibility, they contain the propensity to promote status differentiation.

\section{The Concept of Fit}

In relation to status differentiation there are two things that must go together: a fit that combines both acceptance and recognition. 'Fit' refers to the individual worker's attempt at doing something different with an act and how it is accepted and/or recognized by both workers and audience. Acceptance here means anything that does not fall under verbal or non-verbal rejection. Also, a fit does not necessarily include recognition. In other words, a worker may do something with an act that he considers really 'cool'; however, it may be so 'cool' that it fits into the scene so well that no one bothers to recognize it for its originality or uniqueness. It may fit so well that it is just like evary other normal 
act that is being enacted; it is accepted but not recognized. This kind of circumstance will be referred to as an 'overfit. 8

At the opposite end of 'overfit' you would have the act that is perceived as a 'misfit.' 'Misfit' is where a worker has attempted something different with an act and in show business language, "has laid an egg." The act is recognized by fellow workers as subtracting something from their status. For instance, on a household move giving orders in a humorous fashion was usually greeted in a negative manner. The driver or helper will attempt to combine 'humor' with 'giving orders.' Usually, the humorous tinge to the order is not received by the recipient, and the order is taken at face value, which means that the worker who issued the order has broken one of the informal rules-giving orders rather than advice. Hence, the 'misfit' act is recognized, but not accepted, and the 'overfit' act is accepted, but not recognized. 9

There remains one more alternative: the act that is both accepted and recognized. This is the act that 'just fits.' When an act 'just fits;' status differentiation is the result. When a worker initiates such an act, others become aware of its uniqueness, cleverness, or originality. This kind of act has added quality to the worker's overall performance: It has helped to illuminate skill; it has brought the customer into a closer relationship with the worker; it has built up a mutual respect between al1 the concerned parties. These are just a few of the things that a 'just fit' act may accomplish. Generally, it is recognized as being beneficial to the working group's standards of professionalism. When an act benefits the profession, status is part of the act; therefore, the moment the worker initiates the act and it is simultaneously being recognized by others, the worker is gaining professional status. However, 
the process does not stop here; the worker, himself, will feel separated from and momentarily different than the present others. In other words, he senses autonomy, he is accorded status; and is essentially experiencing status differentiation. 10

\section{Change from Job to Job}

From the above description of 'overfit,' 'misfit,' and 'just fit,' it is apparent that status differentiation may be a difficult task to accomplish. The difficulty up to this time, however, has only been partially presented. For the activity to have some resemblance of harmony, the act must 'just fit,' which, in conjunction with the fact that each job has a potential to be variably different, adds up to the complexity of realizing status differentiation while working on a job. The situation's potential to be variably different from job to job is affected by four important sources. Below is a brief description of each of the four sources:

1) Team Character: The individual makeup of a two or more man team gave a team its own peculiar character and this peculiar character would influence or effect the job differently than another team would.

2) Individual Mood: The individuals at Madrona were people who had good, bad or indifferent days. Their moods could fluctuate not only from day to day, but from hour to hour; and with these mood changes you could have either a turnedon or turned-off individual who wanted either to do something more than just move furniture, or one who wanted just to get by.

3) The Audience: Both management and customer are considered as the audience. Management, because they were not aware of the significance of some of the acts (advice and humor), were not considered as part of the work group itself and were not usually physically present. Therefore, the workers felt that they knew what was happening and management did not. And also, the management was considered as "bosses" when they recognized a good performance, and were considered 
as "shits" when they did not accept or recognize a 'good performance' (a performance considered good by the workers). With management being inconsistent, they gave inconsistent directives which could contradict the professional act.

The customer as 'audience' is self-explanatory: "they are present and they needed to be pleased." The customer is never considered a 'boss'; the mover constantly attempts to stay in control of the situation. Moving is 'his bag' and no layman is going to tell him how to do his "job." To stay in control meant that they had to be aware of their customer's peculiarities and satisfy them by utilizing the professional acts.

4) Type of Job: With the different types of jobs, office move, household moves, sea-van moves, and heavy equipment, i.e., there are different structural characteristics that cal1 for a different intensity of enacting the acts. The household move and the office move are structured differently and therefore the intensity of the acts differs between the two. The office move is an activity that generally requires a large number of men, and involves the movement of a large amount of equipment (both light and heavy), and hence needs a great deal of organization. Also, the office move is under the limitation of a bid which means that the work is directed towards an estimated time of completion; therefore, speed is essentia1. These factors, large numbers, safety, and speed, add up to the fact that giving orders would outweigh the act of giving advice. This means that giving advice would drop in intensity and humor would increase because it would help decrease the status differences that have a potential to emerge out of giving orders.

The household move is structured differently. It involves a smaller number of men; the furniture is usually lighter than office equipment; and the time factor is not as essential because of the important ingredient of 'customer sentiment.' Customer sentiment usually outweighs 'speed.' To be "careful, precise, and meticulous with a customer's furniture does more for a customer-worker relationship than hurrying." To act serious, give advice and, if need be, a little humor is the usual pattern in a household move. The figure below helps illuminate the relationship between act frequency and type of move. 
Figure 5: A General Relationship between Act Frequency and Type of Move

\begin{tabular}{lcccc}
\hline \multirow{2}{*}{ The Acts } & Office & Machine & Household & Sea-Van \\
\hline Coordination & $1 *$ & 1 & 1 & 1 \\
Seriousness & 2 & 2 & 2 & 2 \\
Advice & $4 *$ & 4 & 3 & 3 \\
Humor & 3 & 3 & 4 & 4 \\
\hline
\end{tabular}

*1 represents the highest frequency an act should occur and 4 represents the lowest frequency an act should occur in a particular type of move.

The importance of Figure 5 lies in the assumption that all of the acts are parts of the activity and their variance is dependent upon the frequency of their use. It is apparent that the acts of coordination and seriousness are constant throughout the different types of moves. This consistency between jobs makes it easier for a worker to initiate these acts. The acts of advice and humor, however, are more difficult to use in an activity since they are susceptible to change just in relation to type of move. All four, though, are susceptible to change in relation to 'team character,' 'individual mood,' and 'audience.'

\section{An Expertise with Acts}

This potential for change leads to the implication that the Madrona worker's behavior is not solely determined before the job, but instead his behavior can voluntarily change during a job. The professional acts serve as a guideline for a job so that boundaries for behavior are pre- 
disposed before a job begins. However, the latitude or range of behavior in which a worker may partake while on the job may be quite broad and a number of behavioral alternatives may present themselves to the worker at any moment. To simplify the choice, and, in turn, the acting, the Madrona worker selects special acts that he finds comfortable to handle. By specializing in an act or acts, he is able to become more sensitive to those things that happen on a job that affect his peculiar act which, in turn, increases the probability that he will be able to enact his special act so that it 'just fits.' In other words, by specializing, the worker is insuring himself a greater number of satisfying experiences with status differentiation.

Figure 6: A Comparison of a Worker's Expertise with Each Act by Modes of High, Medium and Low

\begin{tabular}{l|llll|} 
& Coordination & Seriousness & Humor & Advice \\
\cline { 2 - 5 } Einer & High & Med. & Med & Med. \\
Bossie & High & High & Low & High \\
Ray & High & High & Low & Low \\
Ron & High & Med. & High & Med. \\
Jim & High & Med. & Med. & Low \\
John & Med. & Med. & Low & Med. \\
Bill & Low & High & High & Med. \\
High & High & Low & High \\
\hline
\end{tabular}

The modes of high, medium and low are arbitrary and not exact measurements. These modes are like a composite picture over several jobs. 
Specializing may not be the appropriate word to call the skillful manipulation of an act by a worker. The act may be just a natural way of behaving for the worker. Because of this seemingly natural quality, the worker may be in tune to the changing nature of a job so that he knows exactly when it should be injected or bypassed for a better opportunity. Since John and I were beginners in this occupation, we were the only two that were still trying to learn the act of coordination. The rest of them were experts in the issuance of coordination. The remainder of the acts, though, seemed to vary in expertise between the men in this work group.

However, by just specializing, the Madrona worker is not automatically assured of being separated whenever he so desires. Acceptance and recognition must be included if a worker is to experience status differentiation. It is at this phase where ambivalence comes into play. On the one hand, these acts are considered a 'group thing': they strain toward status equality. On the other hand, these acts are also legitimate means of gaining individuality, or more accurately, status differentiation. The former property of the act, status equality, does not necessarily need overt recognition by other group members. The latter property, status differentiation, however, needs a reciprocal action on the part of other group members. 


\section{SECTION II}

TRANSITION INTO DISSENSION: THE WORKER AS AN INTENTIONAL ACTOR

Ambivalence enters the scene when the worker must choose between alternative ways of behaving. The worker as meant here not only includes the actor but also the recipient of the act, who is usually a fellow group member. There are choices: he can either act out or play it safe. To act out simply means that the worker is attempting to be innovative with an act so that he may be differentiated. To play it safe, the worker is attempting to behave in accordance with those acts that are situationally 'normal.' For the moment he just wants to work. 12

Following those two apparent choices, the actor must then make choices concerning the act and how much he should 'stretch' it for the 'fit.' Stretch implies ambiguity between choices, which in turn intersifies the ambivalent nature under which the choice of behavior is made. For example, after making an apparent choice to select and stretch an act, the worker should be aware of several related things: (1) the four sources of situational change (team character, individual mood, audience, and type of job); (2) who shall he direct the act towards--fellow workers, audience, or both; (3) at what moment the worker must decide what behaviors may or may not be situational1y appropriate; (4) whether the acts should be communicated verbally or non-verbally; and (5) the kind of emotive connotation that will be applied to the act. These are at least some of the things that a worker must be aware of when deciding upon possible lines of action. When you add these choices up with the fact that you're constantly moving without much time for contemplation, the 
scene hints heavily at a decision-making process of ambiguity and ambivalence. This simply means that the worker is never really sure whether the line of action he has chosen will be accepted and/or recognized until he does it (that is, if the worker desires harmony).

\section{The Recipient: 'Doing It'}

The instant the Madrona worker does his action the ambivalence that was surrounding the decision is momentarily resolved. Since this section is dealing with harmony and status differentiation, let us say that the worker has decided to make the apparent choice of doing something different with an act so that it 'just fits.' As soon as the act has been transmitted, the recipient of the act becomes the primary actor. The primary actor is the one who must make a choice, and the recipient is placed in that kind of position. The alternatives that the primary actor must choose from are, on the one hand, to acknowledge the act as being beneficial to the team aura, or, on the other hand, simply not to notice the act, or he may communicate rejection of the act.

The recipient of the 'supposed' 'just fit' act is quite aware that both of these alternatives may promote dissension. The first alternative of accepting and recognizing the act can promote dissent by being used too frequently. For the sake of harmony the recipient might be more automatic than sincere in his response to the worker who desires status differentiation. The frequency of accepting and recognizing any so-called act results in the appearance of the act as being automatic and therefore losing its significance in relation to the originator of the act. The worker feels bored; status differentiation is meaningless; the consequences of dissent grow increasingly probable. ${ }^{13}$ 
The second alternative that the recipient may not be aware of is more flexible in the kind of behavior that may be called out from the original worker. For instance, the recipient knows that his fellow worker may either remain silent and discard the incident for the sake of harmony, or reject the worker's silence or communicated rejection. The latter behavior may be an aspect of dissent or may give rise to dissent.

As long as the recipient worker is aware of these alternatives and he, himself, wants harmony in the job, he senses, knows, and experiences ambivalence. The recipient feels an unsureness that can only be resolved by acting on one of the alternatives. In other words, ambivalence is resolved at the moment of acting, then shifts to 'other,' who then must choose a certain way to act in response. The alternatives differ between Individual workers, and ambivalence is present only as long as the worker is aware of the alternatives.

Yet, there is still something missing in relation to the worker at Madrona. So far, his behavior has been explained in the light of some kind of awareness on his part. This, in turn, implies two things: (1) that his acts are a kind of program that has some kind of flexibility for innovation; and (2) that he is in control and everything he does is quite intentional. However, there is a third explanation--the unintended act or, more specifically, spontaneous behavior.

\section{Spontaneous Acts}

While in the event of moving, the Madrona team members were not prone to spontaneity. A spontaneous act as used here means behavior that appears to be misinterpreted from what the original actor had intended or unintended. The consequences of spontaneous behavior may be dissension. 
or harmony, depending again on its 'fit.' As compared to intentional behavior, or intended acts, spontaneous behavior only fits into the 'misfit,' and 'just fit' categories. A spontaneous act that 'overfits' is inconsequential in terms of producing any reaction on any of the participants: it justdoes not appear to have any significance to the originator or the recipient(s). It is apparent that even though the act may be spontaneous, it is still adjoined to the situation. It is the act's newness to both actor and audience that makes it spontaneous; and newness to both the Madrona worker and fellow workers is difficult to accomplish.

In relation to harmony, the spontaneous act appears to be more peculiar than the intended act. The consequences of a spontaneous act that is a 'misfit' and a 'just fit' can be either harmony or dissent. The spontaneous act that 'misfits' can be received by the actor in two ways. On the one hand, since he had not vested much interest in it (since there were not any conscious alternatives or choices involved), he may simply not care. On the other hand, since it was not intentional and the worker does not really feel responsible for it, he may become quite tense, anxious, and emotional about justifying the negative response. $^{14}$

The spontaneous act that 'just fits,' however, has a potentially long career ahead of it. In other words, no matter what the actor thinks of the recognition and acceptance of this unintentional thing he did, it is highly probable that it will become a part of the repertoire of professional acts. What is meant by "what the actor thinks" is that he may not necessarily desire status differentiation at that moment of initiating the spontaneous act. He may just want to work along with the other team member(s) in the 'appropriate manner,' as defined by the situation. He. 
may feel that the attention he is receiving is unwarranted and uncomfortable since he did not want to be different than anybody else at that time. Another reason for shunning the positive response to his spontaneous act is that he may feel that he has lost control of the situation. He did not intend, or plan, or decide on the act--it just happened; therefore, he is asking himself "what happened?" He has a sense of being momentarily lost from his fellow workers, audience, and the 'general movement' of the scene. However, regardless of the way the originator of the spontaneous act feels, it will usually be adopted as a part of the professional program by some member of the work group.

The above case on spontaneous acts may be overstated; however, it does point out an important concept in relation to this particular work group. This work group, as already noted, is structured around status equality. There is a constant strain to portray those acts that are accepted by the work group members. The formally recognized status distinctions are held meaningless by a majority of the Madrona crew. What counts in relation to the notions of professionalism is how well one can stay within the bounds of the acts and still differentiate himself. The implications of this are important for they point to the fact that status differentiation in this kind of group is very difficult to realize and experience. This statement is illuminated even more by the lack of spontaneity that exists between the working members on a job and the very minimal number of spontaneous acts that were observed that became a part of the professional acts.

During the period of observation, two spontaneous acts were recorded that 'just fit,' and were adopted by the Madrona crew; both were spontaneously projected in directions that were not actually conducive to the 
worker-customer relationship. Both acts were picked up, however, and placed into the humor category and later used, whenever it was appropriate, in front of management, customer, and fellow workers. These acts are described below:

1. The first spontaneous act that was observed originated with Ray (helper), who, at that time and maybe most of the time, had an unfriendly relation with Bob (driver). Bob had been pushing Ray during a job and finally Bob did the unforgiveable thing--he attempted to order Ray to move something better. Ray responded in a hostile and aggressive manner by literally shouting "Suuure! Bob can do it! Pooor Mother Fucker!" From then on the latter phrase was unacceptable in front of the audience, but was used quite frequently among the workers. However, the first phrases were adopted and built on so that a whole repertoire of this kind of humor eventually was built up under the manufactured label of 'rapping humor,' and was used virtually everywhere one felt it appropriate. It was quick, short, sporadic, and fit into the movement of a job with ease.

2: The second spontaneous act was observed from a first person standpoint--me. This act came about after Ray's, and again was placed in the flexible, elastic humor package. When doing this particular act, I had no idea what I was doing--except carrying a very heavy piece of furniture and knowing that I was getting very tired, and felt like simply dropping it. However, the response that I was receiving was not befitting to my predicament. "I was working damn hard; why were they smiling, chuckling? They should be more serious and encourage me, instead of intimidating me." I was feeling a little anxious, resentful, and lost. However, as the situation became clearer, through more responses, I found out that I had originated a new kind of humor--'facial humor.' While carrying the heavy piece of furniture, my face was going through all kinds of contortions. (this is not considered proper if you are a professional; the customer will start to worry) which struck the rest of the team as quite funny. (Anyway, I felt like I had.done something; I did feel separated, from the first person standpoint $) 15$

These are two examples of spontaneous acts that were recorded--not very many; however, one must remember that the entire scheme of this paper is focused on working the move. Even though there appeared to be more spontaneity outside of the actual moving, those spontaneous acts 
that were actualized on the move were mostly 'misfits.' The above were the only two that were recorded as 'just fitting.' In other words, the spontaneous act that 'just fits' is what it means; it happens in a situation, like a move, and from then on its appropriateness is upheld in. that situation from which it originated. Other implications are that status differentiation is experienced by degrees, rather than as a constant. Also, the lack of observed spontaneous acts points to the fact that there is a constant strain to conform, as much as one can, to the professional acts. This, in turn, leads into a discussion on dissension.

\section{SECTION III}

GROUP AND INDIVIDUAL DISSENT:

GETTING AWAY FROM THE PROFESSIONAL ACTS

\section{Introduction}

Dissent in regards to the Madrona work group took two forms: group and idiosyncratic. Also, dissent can emerge and strike out in two different directions: toward and away from the professional acts. Both, however, take the form of 'stepping-out.' All or portions of the group members may step-out together to initiate group action, or individuals may step-out to inftiate their own action: Both actions initiate a momentary activity that gets away from the professional acts. Dissenting by stepping-out can resemble anything from open rebellion to passive resistance. The Madrona work group is no exception. Moments of dissent, both group and individual, were more frequently observed when the first act of coordination was being established with some difficulty. The following discussion will focus on this act as reason for group dissent 
and the related forms of dissent. The individual will be brought in next and conjectures made concerning reasons for idiosyncratic dissent. Following is a description of the three ways in which Madrona workers step-out while working on a job.

\section{The Madrona Group: Reasons for Dissent}

The discussion will focus on the Madrona working group as a whole and describe some reasons for group dissent. What kind of behavior contained a high probability for all or part of the group members to dissent? During the investigation three reasons were found that had potential to cause dissent: (1) inappropriate frequency of a particular job's acts; (2) establishing rhythm and movement with 'too much talking, '; and (3) the "too many chiefs and not enough Indians" syndrome. The first reason is common to all the jobs. Reason two is more common to a household move; and reason three is more common to the office move. All of the reasons are specifically dealing with the act of coordination.

As recalled from Figure 5, jobs had a particular structure which in turn influenced a difference in the frequency of two of the acts--advice and humor. The office move is characterized by orders and the frequency of advice is decreased. Humor is intensified to help offset the strain caused by the issuance of orders. The household move is characterized by advice and a seriousness that is intensified for the benefit of the customer, which, in turn, subtracts from the frequency of humor. The probability for dissent would increase if this particular frequency was altered. $^{16}$

For instance, it is perfectly clear that an office move with at least two teams of three or four men needs some kind of immediate organi- 
zation. For example, to advise rather than give orders in an office move would greatly retard immediate organization for speed and efficiency. No matter how directly one may give advice, it is still more time consuming than giving a direct order. Without immediate organization the workers begin to feel very unprofessional in front of their audience--the office workers. The worker begins to feel frustrated for he is either losing or not gaining control over his professional. acts. The remainder of the professional package cannot be utilized until the basic act of coordination is established. Without this first essential act, the other acts lose their professional significance. Therefore, establishing group status becomes increasingly difficult with the increase in time that it takes to coordinate the workers' activities. With this twofold difficulty of time and coordination there is the likelihood that the occurrence of dissent will increase.

On any type of move there is a continuous strain to establish rhythm. "Setting a pace" probably depicts this type of rhythm the best. Coordination, of course, is in part the establishing of rhythm. Once a rhythm has been established where the worker who is loading one piece at a time without too much hesitation between pieces and the helper is able to haul the items so that he can fit this loading pattern, then the movement of the move can be slightly increased or decreased. Once this pattern has been worked out, it appears smooth as compared to a sporadic movement, and in turn appears more 'professiona1.'

When the rhythm of a move is interrupted, problems can occur. So long as the interruptions are directly related to the move itself (large pieces, jam-ups, a falling tier, etc.), the problems can be handled in a manner that satisfies the workers' notions of professionalism. However, 
if the movement and rhythm of a move is interrupted by external forces, then the problems may be professionally unreconcilable. For example, the most common interruption of this sort was "talking too much." That is, talking too much to the customer about unprofessional things--things like one's personal virtures (physical strength, family, education, etc.) and the virtues of furniture moving (income; telling customer how skillful furniture movers are, or simply bragging about the occupation) 17

These latter kinds of interruptions are external to the workers' notions of professionalism, for both retard the task of working toward a status because of three assumptions. First, talking about one's personal virtues is too idiosyncratic, which means that the other team members may feel belittled. Second, overtly bragging about the profession of furniture moving is considered by the workers as a phony way of proving something. The third point is generally related to the above two and is simply that external interruptions of the rhythm and movement of a move also obstruct the performance of the acts. The above reasons illuminate the assumption that they all retard, in one way or another, the development of a group status; therefore the probability of dissent increases. The cliché, "too many chiefs and not enough Indians," is probably apropos to any task-oriented group that has shades of equality transcending its rank and file. Of course, there is nothing wrong with the 'rank and file' being chiefs once in a while. However, during an office move, "too many chiefs . . ." meant that there were entirely too many individuals and not enough group members; they were acting outside of the first law of this working group--coordination. More importancly, there is one factor that makes "too many chiefs..." problematic; instead of being together, the chiefs issue contradicting orders and total bedlam is the 
usual result.

Of all of the reasons for dissent, this one is probably the most damaging to the image of a professional furniture mover. It is a disorganized disaster. Fortunately, it was not a common occurrence and only once did it have a lasting effect on an office move. By 'lasting effect' is meant that the move was bad from beginning to end. No one knows what he is supposed to be doing. For instance, one moment a worker is loading an elevator, trying to attain some kind of rhythm; the next moment he is tearing down a desk. Then, when multiplying this job-shifting by eight or more men, one can safely say that "confusion reigns," so much confusion that dissent takes on a diffused character. It is not directed toward any one thing, nor does any one worker dissent like any other. This prolongs the bedlam, the confusion, and the result is a disorganized disaster. $^{18}$

The implications of this last statement are that dissent by getting away from the professional acts may in turn help re-establish them in a move. As observed during office moves especially, this kind of dissent usually involved part or all the team members dissenting in one direction. A direction towards the obstruction; that is, not allowing the acts to be played. Hence, the next two blocks of discussion will center around these two alternative directions of dissent.

Drastic Action: Dissent Away to Establish or Re-establish the Professional Acts

'Dissent toward the professional acts' sound like a tautological statement, for it appears as though it means the same thing as a 'strain toward status equality.' And, in part, it does mean a 'strain' of sorts. 
Dissent toward the professional acts, however, is defined as something more abrupt or drastic than a continuous strain. A more fitting definition is as follows: the drastic re-establishing or establishing of particular key acts that have been or have not been situationally defined so that other acts can be incorporated into the situation for the purposes of 'illuminating' a professional performance. The key words in the above definition are the 'drastic re-establishing or establishing or particular key acts.' For the working group at Madrona, 'coordination' is a key act and when the act of coordination is not becoming situationally defined, drastic action may be needed to establish the act of coordination. At a move the workers may employ two kinds of dissent toward the professional acts: (1) shifting and re-focusing the responsibility of leadership; and (2) removal of a 'clog' by physical or verbal abuse.

Leadership within the Madrona work group is tangential. The leadership was never solid nor was it constant between jobs. There was never one leader in the Madrona work group, but there were three or four. A more fitting description of Madrona leaders is 'momentary leader(s).' They emerge or arise for a fleeting moment, do the act that benefits the performance and thenimmerse back into the group. In the middle processes of a move this mode of leadership is very conducive to the workers' notions of professionalism. It initiates a team activity that helps the demands of status equality and status differentiation. 19

However, momentary leadership does have its drawbacks, especially in the initial phases of a job when establishing coordination. With momentary leadership the team members are more apt to shift and re-focus on another member much more quickly than they would if there were a strong, charismatic, 'great man' kind of leader directing a move. There. 
are situations where the leader may need time to find the best way to coordinate the team(s). With the availability of other 'leaders,' however, and by the fact that he is attempting to be constantly highlighted as a leader, it does not take very much time for the workers to locate and isolate him as the culprit who is not allowing them to play their professional acts. Hence, his directives are subtly rejected and the workers begin to coordinate themselves with the help of one, two or three of their fellow group members.

Usually two members of the Madrona family would direct the office moves. Management's function was to set the team up, give each team its area of responsibility and then give each team the overall stratagem of a move, after which the team members would coordinate their individual activities and simultaneously coordinate their team's activities with a related team. Management would usually not intervene at this latter phase unless a better method of coordination of individuals and teams appeared. However, the concern here is with the first phase, where management is occupying the leadership position in attempting initially to coordinate the Madrona work group.

It appears that a chain of events would occur where the most minute detail of coordination would be worked out by the individual worker. Management has the responsibility of establishing the first initial links, after which group members would establish other 'links.' When the first initial links are not visible in the sense of a structure that is composed of teams, responsibilities and/or overall strategy, the workers begin to find themselves in a real dilemma. Frustration and tension creep into the working group. Individually they are confronted with three apparent alternative causes to the problem: it is 'I,' one or all 
my fellow workers, or management (customer does not enter as an alternative, for he is not given a place in the initial phases of the move).

Again, even with the making of dissent, there are ambivalent properties. The worker does not know what the problem is, and to find out, he begins an inquiry into the source of what is deterring them from the act of coordination. For instance, the worker begins the inquiry by grumbling within earshot of another worker; the other worker will usually respond by grumbling back about how "shitty the move is going . . . I don't even know what I am supposed to be doing." In short order, the worker and his fellow workers know the source of the problem--management. However, the ambivalence at this time is only resolved between the workers. Now they must somehow resolve the ambivalence that is surrounding their alternative ways of either doing nothing or going against management's lack of leadership by choosing another leader. With the latter they do it by dissenting.

The potential leaders can be found among the members who make up the work group. In an office move the potential leaders would be Einer, Jessie, Bill, and Ray (when he felt like it). Once the workers shift and focus on a potential leader, the act of coordination also shifts. If the worker responds to these demands of leadership, he would have to establish the primary links that management's lack of leadership failed to establish.

of course, the dissent does not mean that management is experiencing a coup; more accurately, it simply means the management's directives are now being interpreted by either a11 or part of the aforementioned leaders, who then direct the rest of the workers. The interpretation of management's directives is such that both expressive and instrumental 
connotations are applied. The worker(s) who have been momentarily chosen by fellow workers to lead and initially coordinate them must do exactly that; for now there is the added responsibility of arresting the built-up tension that is being produced by management's inadequacies. Fortunately, the working-leaders do not have to perform this twofold job over a long period of time. Instead, they must get some resemblance of coordinated. activity into the working group in a short, but hectic, period of time. During this time they have to arrest tension by applying a little humor, and issue orders affecting the individual makeup of the team, the team's responsibilities, and the move's overall stratagem. Once the resemblance of coordinated activity spread throughout the work group, their duties as leader become minimal. Now, the drama of moving is finally able to unfold. 20

As already mentioned, another reason for dissenting is the worker who hinders the rhythm and movement of a job. This worker is appropriately termed a "clog." The working clog can be found in the initial, the middle and the end of a moving process. His notoriety, however, is manifested during the middle processes, since the humdrum of initially coordinating men and activities has been smoothed out. The middle processes usually have an established rhythm that allows the worker to concentrate on the remainder of his professional acts. A clog unintentionally disrupts the overall performance, and unthinkingly is retarding the workers' attempts to build up their group status. Focused dissent takes shape in two forms: (1) verbal abuse is usually the first in a two-step process; and (2) physical abuse is the second and most extreme form of dissent. It is evident from the above that 'new guys' are more 1ikely to be clogs than are the "old guys" (old is not necessarily in terms of age, 
but in terms of years of experience). However, there were instances where an 'old guy' became a clog. Once the verbal abuse began, however, he did not remain a clog for long. Verbal abuse would take many forms. The two most common forms were ugly humor and direct confrontation. (Ugly humor is humor that is superficially funny, but subtly pointed toward a clog's vulnerable person.) "God, you're fat, Bob," or "Poor Ray has had too many Bennys" are examples of ugly humor. With an "old guy" ugly humor would be exceptionally easy for he has been around long enough that his "sore spots" are common knowledge to the others. For example, Bob being overweight, Bob being in debt, Bill an alcoholic, Vance an egghead or a rock, Einer's wife problems could be a sore spot with these men. When a worker became a clog, his sore spots were used in a most discreet but pointed way.

Even the 'new guy' can become vulnerable, for he is trying to make the grade as a furniture mover and this in itself can be his most tender spot. However, a more common occurrence with a 'new guy' clog would be direct confrontation. Since the informal bonds had not yet been tightened, he would still be considered an outsider who was not as yet a member of the Madrona group. Therefore, he was handled in a less delicate manner than an old member of the group would be. Direct confrontation would take a very special order. First, the workers would let the audience know, in a subtle fashion, that the clog was a 'new guy.' Second, the 'new guy' would be given hints that "talking to: customers about things not pertaining to the move is taboo." And, finally he would be called "lazy," "not physically capable," or a "new guy who had better pay attention to moving because there is a lot to learn." 
Now, if the latter does not make an impact on a 'new guy,' the movers will attempt to teach him a lesson or remove him from the moving end of the operation by physically abusing him. The former mode of physical abuse is used to show the new guy that there is much more to moving furniture than apparently meets his eyes. The other workers will carry a piece of furniture (like a sofa) down or up a flight of stairs and do things with the piece that add weight to the other end where the 'new guy' is struggling. This added weight, with a few jerky motions, is not necessarily physically dangerous, but it does have the capacity to be physically excrutiating. Hence, the 'new guy' should be able to add up all of the verbal and physical abuses to highlight his wrong doing. Thereafter, he should begin to pay more attention to the move, asking relevent questions and hence cease being a clog.

There is one more alternative the workers can choose if the 'new guy' still persists in being a clog (this is even after talking to management who may not be able to do anything). Physical damage is, of course, the last resort measure of removing a clog. However, the 'new guy' symbolizes a real threat to their aspired professional standing and equally, or maybe more important, he is a threat to their physical well being and eventually their livelihood. It is not difficult to crush someone's toes, fingers, or slip a 'new guy's' back. Once it is done, the 'new guy' is out and the clog is removed. 21

Physical abuse to the extreme of physical damage is the most specific, and in itself the most extreme form of dissenting toward the work group's aspired status. However, all of the above methods of dissent show one common characteristic--they are all outside the boundaries of the professional acts. This could be because whatever is causing the 
disturbance is also outside the boundaries of the professional acts, and the only way of restoring some resemblance of the acts is either to bring it back or cut it off.

Every example that was given exemplified a focal point toward which workers could resolve their ambivalence by choosing a line of action and therefore doing something to that object which is obstructing the process of gaining group and individual statuses. Once the reasons for the obstruction have been established by the workers, or by part of them, through verbal and non-verbal communication they are able momentarily to dissent as a group. However, what happens when the ambivalence cannot be resolved by the group? The fact that the workers, or even a part of them, cannot agree on a focal point means one thing--individual dissent.

\section{The Madrona Worker: Reasons for Dissent}

Before there is a discussion of the actual moment of an actor's dissent, there will be an explanation of some reasons for individual dissent. During a moving job, what prompts a Madrona worker to 'step-out?' When one cannot find answers to bothersome questions, he is in a state of ambivalence, especially if the questions themselves contradict each other. Sometimes the answers are found within the situational context, at other times they are found outside the situation. In relation to the job, the professional acts are a part of the situation. Sometimes the worker has to go outside of these acts to find answers to unreconcilable questions. These contradictory questions arise because of two reasons: (1) lack of recognition for doing something the worker considered new or unique; and (2) too much recognition. Both of these represent status equality and 
status differentiation through the notions of confinement and boredom; confinement being associated with lack of recognition and boredom being closer to too much recognition.

When working on a moving job with other Madrona workers, it becomes an extremely difficult task to be anything different than your fellow team members. A worker attempts to tell jokes, be serious, highlight his coordinating ability or suggest pieces of furniture for loading. He may combine acts like coordinating and being serious (carrying a piece of furniture and placing his hand between the furniture and the wall, thereby having his hand hit the wall before the furniture and preventing damage) or do any other number of combinations to illuminate his skill, more or less his uniqueness. However, all of these intentional efforts at wanting some kind of attention and recognition may not be actualized between the worker and audience (in this case the usual audience is the other workers). The audience either simply neglects or silently rejects the worker's overture at separation, With the increase of failures in experiencing status differentiation, there is the increasing probability that this worker will 'step-out' and dissent.

When a man is attempting to gain recognition by means that are considered by, him and others as being situationally appropriate, he probably wants this attention very much. It may be very important for his identity as a furniture mover. He would like to be recognized as an important member of the team and establish an identity which is within the framework of the work group rather than outside of it. To accomplish this, he must work within the structure of the professional acts. In turn, he may not be receiving the attention or recognition he so desires. To himself, his status as a furniture mover is questionnable. His team 
members may think he is an excellent furniture mover; however, if they are not receptive to his demands for recognition, "how will he know?" Questions arise about his own status as a furniture mover.

As soon as the doubts arise about his status as a furniture mover, questions concerning other aspects of his life begin to impinge on the moving scene. The Madrona worker is not only a furniture mover, but he is also a home owner, a car nut, a married man, a carpenter, and a person. He is an individual whose personal makeup is a conglomeration of all of the above-mentioned things, plus many more. If he does not feel important during a moving job, and continues to remain ambivalent about the contradicting questions about himself, he may start losing himself into the work group as an unimportant entity. He feels confined in not being able to tell everybody that he is a home owner, a college graduate, or that he is strong. He may feel an overwhelming urge to step out and do it. If he does, he is momentarily resolving his ambivalence by dissenting on the job.

Too much recognition brings in the same kinds of dilemmas as lack of recognition, but the feeling of confinement changes to one of boredom. The dilemma of whether to be a furniture mover and/or an individual changes with the emphasis of too much recognition. Much of the discussion so far has been to illuminate moving as an exciting trade. However, this is not the case all of the time, for there are moving jobs that are routine.

It is usually during one of the seemingly routine jobs that one becomes frequently recognized for doing hardly anything at all. During a job of this sort, one begins to doubt the status of furniture moving. He himself begins to doubt his own conceptions of it as even a trade. "How 
come it seems so boring today?" or "Where is this sense of fellowship. with my tean members?" are a couple of hypothetical questions that may arise from a routine job. Whatever the question, it probably has something to do with the virtues of furniture moving.

Ambivalence enters the scene when the worker has a choice available among: (1) doing something with the acts that apparently have lost some of their meaning during the job, or (2) a choice that involves doing something that will cause some excitement by stepping-out and decreasing boredom, or (3) he may do nothing and continue to be ambivalent about the situation. The second alternative seems like the most likely choice for a line of action that will change the job from one of an automatic process to a more dynamic one.

He may step-out to get some kind of excitement into the move, even though this excitement may take the form of anger. However, even with anger, the move will lose the appearance of a superficial, automatic process. The definition of the situation is in flux, and hence expectations are momentarily lost and the workers may become actors again in redefining the situation.

\section{Dissent Away: Individual Dissent}

During a job there were instances when individuals in the Madrona work group would dissent. They became unprofessional. These moments of individual dissent took three basic forms:. (1) intensifying a professional act beyond situational appropriateness; (2) choosing alternative Iines of action that were 'out of place'; and (3) acting too individually, or a more appropriate term, idiosyncratically. Individual dissent in any of the three forms is caused by attempting to resolve contradicting 
questions that arise out of the concepts of confinement and boredom.

'Too much professional act' is either intensifying an act to the point of ridicule, or utilizing an act too frequently. Intensifying an act to the point of ridicule occurs basically when a worker is overacting; it takes on the appearance of phoniness. From the audience perspective it fits into the earlier category of a 'misfit' act. However, from the actor's perspective it is over-acting because he either feels confinement or simply is bored silly. His performance may be responded to as being ridiculous or absurd. The response to the worker's performance is usually transmitted to him in the form of ridicule. That is, of course, if the other workers are attempting to establish the professional acts. If they are not, if the job has disintegrated beyond the point of recovery, the other workers may be 'stepping-out' as well. Then his over-acting may be applauded by laughter or imitation. ${ }^{22}$

When 'acting out of place,' a worker behaves in a manner that may be appropriate to other work-related activities, but this same behavior is not appropriate on a moving job. For example, when working in the warehouse, the movers were working at tasks that were unrelated to their furniture moving 'skills': unloading box cars of tires and glassware cartons, sweeping, breaking down boxes, helping warehousemen fill tire, rug, washer or dryer orders, etc. There were many instances when movers would 'rank each other out,' restore old antagonisms, or initiate new antagonisms when doing this kind of work. The warehouse was a place where this kind of behavior was tolerated for it did not damage the compatibility that the workers needed on a moving job.

However, there were moments on moving jobs when antagonistic behavior would burst out with a vigor that far surpassed its counterpart in 
the warehouse. On a moving job antagonisms became potentially dangerous. There were antagonisms acted out on moving jobs that took on a pronounced character of dissent ('pronounced' because overt anger between team members on a job is very damaging to their sense of fellowship). Jim and I had been working all morning in the warehouse and were "ranking the hell out of each other." During the afternoon we went on a moving job and both of us were quite bitter about the morning's events. When we started the job, we didn't say a word to each other until Jim made a snide remark and I responded by telling him to "keep his mouth shut." The move was a miserable affair. Because antagonisms were released in one place, it is not hard to conceive of them emerging in other situations where moments of tensions, frustrations and anxiety are not uncomon. Overt anger, however, is not a common form of 'acting out of place.' A more common occurrence was when 'acting out of place' took on a milder appearance. For example, of all kinds of behavior that could be considered 'out of place,' swearing was the most common. The movers, while working on a job, considered swearing unprofessional for they believed that swearing to the customer meant that something was wrong with their performance. Their notion of professionalism, however, means that they paint a picture that transmits to the audience a realization that "these Madrona workers can handle problems in a very workman-like fashion" and "the job is rough but the men at Madrona handle it in a professional manner." Swearing contaminates this picture, for it transmits the opposite of what the picture is expected to portray. Swearing in the warehouse, lunchroom, truck cab, and the back of a truck is normal; however, swearing in front of the customer or in the house or office (because you never know where the customer might be lurking) is 'out of 
place.'

Once a person had been accepted in the Madrona work group, there was quite a wide latitude of behavior he could use, without any kind of sanction. Idiosyncratic behavior (behavior that appears peculiar to only that person) was a very common occurrence whenever the group members were interacting. That is, jt was common in any place, except the moving job. of course, one can argue that some idiosyncratic behavIor is always present in a moving job, just by the individual worker's way of treating the acts. Also, one can argue that to some degree portions of the workers' idiosyncratic behavior have merged together to give the Madrona work group a separate identity from any other furniture moving group, just as the other groups have an identity separate from the Madrona group. However, what is meant by 'too idiosyncratic' is not necessarily acting 'in or out of place'; too idiosyncratic is behaving in a manner that overtly identifies one worker as something other than a furniture mover. Be it either a negative or a positive identification, it remains a means of dissent--a way to establish a real separation from the work group as an 'offender.'

It is difficult to categorize idiosyncratic behavior. It comes into the scene in a sporadic and inconsistent manner and runs a range of behavior that is even further removed than 'out of place' behavior. Idiosyncratic behavior will be discussed in terms of specific individuals rather than general categories of behavior.

Einer, 'the playful and troubled one'; Jessie, 'the put-on artist and strong, silent one'; Ray, the 'antagonist and one who likes to play dumb'; Bob, 'the singer and the one who always has the worst problems'; Ron, 'the cartoonist and the Bostonian'; Jim, 'the physical speciman and. 
the mouth,' and Vance, 'the educated one and the bumbler': these are the men at Madrona with a couple of descriptive idiosyncratic titles. To illuminate idiosyncratic behavior as dissent, Jim will be discussed in more depth.

Although physical strength is held highly by most of the men at Madrona, it was never acted out in an overt manner. They did not show off their strength as Jim did when he decided to dissent. He would attempt to make a major production out of carrying a very heavy piece. Where two men would usually carry such a piece, he would attempt to take it himself and usually succeeded. For example, during a disorganized office move when a portion of the workers were attempting to dissent toward the professional acts by focusing on momentary leaders, Jim was doing his idiosyncratic 'thing.' Within the confusion of attempting to establish coordination, Jim, in his Tarzan-type hairdo and skin-tight T-shirt, was mouthing and antagonizing Bob into a contest of physical strength. With bitter feelings on both sides Jim carried a hundred and fifty pound cash règister to the van; Bob did not. Even though it could be considered a meritorious feat, the remainder of the workers expressed their dissatisfaction in not too kindly terms. In this case; it alienated Jim even more; everybody ended up as targets for 'the mouth' and he continued to display himself as the strongest of all the men at Madrona. Jim was not the singular cause for this particular office move remaining in a state of havoc, but he did have a partial influence on other workers who turned from a form of group dissent to dissenting by each stepping-out in his own fashion. Naturally, this had a considerable impact in slowing down the process of establishing coordination. 
In actual events where complex behavior patterns are occurring, there exists a very thin and at moments an amorphous line between appropriate and inappropriate behavior. The behavior of the Madrona workers is not any different while working on a job. At one moment a worker may be acting away from the professional acts with other team members. At another moment he may be doing his own thing without support of other group members. In this investigation both were considered as forms of dissent. Dissent is not deviant behavior. Nor is it considered right or wrong, black or white, Hopefully, this last discussion has illuminated dissension as just a part of working as a furniture mover. 


\section{CHAPTER V}

\section{CONCLUSIONS}

\section{What Has Been Discussed: A Brief Summary}

Erving Goffman (1961:96) mentions that. "when the runs of a situated system are repeated with any frequency, fairly well developed situated roles seem to emerge: action comes to be divided into manageable bundles, each a set of acts that can be compatibly performed by a single participant." The workers at Madrona Transfer \& Storage have, in relation to the moving jobs, placed actions into 'manageable bundles.' These bundles have been termed professional acts. These acts are most prominent while the workers are moving furniture. The acts' compatibility with the moving job arise out of their capacity for the worker to realize both status equality and status differentiation. These acts of coordination, seriousness, humor and advice, fit into the drama of moving.

Once the job begins the team members will begin building them up. Since they are working at the acts together, they are simultaneously experiencing status equality. The very nature of the acts themselves strains toward the removal of status distinctions between the workers. The status of their occupation depends upon their technical skills and their skills at working as a team, a well polished and well greased team. The customer likes the appearance of serinus men working and doing a job for him in a highly coordinated way. It looks professional and the customer grants them a higher status than that which was expected by the workers initially. 
However, to be granted status as good furniture movers is simply not enough for the Madrona workers. They want more of themselves and of the customer involved in the drama of the move. By involving themselves, they feel that the work becomes more enjoyable and, in turn, less work. By continuously building on the acts they are performing, theyare giving the move a touch of drama. Also, in the same token, while building up these acts, they are bringing the customer into the move. By building up these acts, the movers are gradually releasing data about themselves as people and this seems to have the effect of erasing customers' notions of stereotyping these men as simply being furniture movers and nothing else.

However, this process of building up the professional acts is not smooth, nor is it meant to be. The mere mention that the workers are building up these acts, between themselves and customers, implies a challenge to remove and/or maintain pre-defined conceptions of people. Ralph Turner (1962:25) indicates that "interaction is always a tentative process; a process of continuously testing the conception one has of the role of the other." Being tested is probably much of the ambivalence that surrounds the alternative lines of action one may choose for the intent of realizing status equality and/or status differentiation. When the worker is able to succeed in realizing both status equality and status differentiation while behaving in accordance with the professional acts, he is in harmonious relation with the situation.

However, the acts themselves have enough structure that at moments they do not offer a worker enough leeway to behave. They just do not have the capacity to do what the worker may want to do. He must resolve the ambivalence that on one hand he. is a group member, a furniture mover, 
and a team member, and on the other hand he is an individual with unique qualities and he may feel that no one seems to realize these virtuous things about him. He must rid himself of this anxiety, this ambivalence, and choose a line of action to show he is different; then he must do it, actually to resolve the ambivalence. He may be received in a positive or negative fashion by his fellow workers. If he is received positively, he may feel good for a while, and he may even learn something new about himself and his fellow workers. If his actions are received in the negative manner, he may feel anger, or feel affronted or put down for a while and again he may even learn sometning new about himself and his fellow workers. However, it does not take too long for him to start thinking in terms of his place in the work group. If the professional acts are not a part of the choices in behaving, and he does behave away from the acts, he is again dissenting. Because of the constant and sporadic dissent, this worker may just change or create new acts.

\section{Is There Any Importance in What Has Been Discussed?}

Does this study have any relevance to the field of sociology? The answer to this question is probably determined by one's sociological perspective. Some might say "it is interesting--so what?" while others might say "it is relevant--but it is only relevant to the Madrona work group." To address the former would be a waste of time; hence, the latter will be addressed with the remainder of this discussion.

In many ways the discussion of the Madrona work group parallels many of the experiences one has had in other types of groups: discussion groups, peer groups, friendship, etc. As compared to these other groups, the men at Madrona experience basically the same phenomenon; however, there 
is one slight difference--they are physically working, moving and their ideas and expressions are tied into this kind of work. For example, in comparing this work group with a peer group, one can readily see that restrictions placed on the former are greater than those placed on the latter. However, these apparent restrictions are there only when the men are working together on a job, and the restrictions are there because of the nature of the work they are doing. Also, they are earning a living by performing these tasks in a workman-like fashion.

However, what happens when they are sitting in the cab of the truck, or chatting together in the lunchroom, or visiting each other in the tavern? As they enter these situations, the work group begins to resemble the characteristics of a peer or friendship group. Again, they are experiencing the group. The acts may change but the counter-tendencies of equality and differentiation remain.

The workers are the same, but the character of their group changes. Now they can sit down with each other and express themselves without the impinging time element of working. They do not have to worry about performing as professional furniture movers in front of an audience. Now they can sit down as a small group of men and talk.

Each worker now may become more aware of his fellow worker's attitudes and differences. This, in turn, helps the individual clarify his attitudes on others and helps him at least understand the minimal aspects of the day's encounters. He is allowed to express himself more freely now and maybe say things about his own and others' behavior while they are working. They can talk about customers and new tricks they learned during the day. If they were not recognized for some important act during the day, they may be now. A worker who was criticized during the day for 
acting away from the acts may now find himself a target for jokes and hilarity, the seriousness of his act now changing to one of humor. Hostilities that axose during the day may now be smoothed over.

Likewise, hostilities may emerge from such sessions. The tavern session--through drinking and the mysterious qualities of the unconsciousness slowly rising to the surface, old hidden grudges may give rise to very real observable ones. Simple things, like not being able to talk because of some blabber mouth who is getting all the attention or being called on to express yourself when you do not want to, may give rise to dissension in these informal settings when interacting with peers and friends.

These experiences, though, are not depicted in the group alone, but the worker carries these experiences out into the larger society. He is able to conceptualize the limitations placed on his behavior when entering the external world. He is able at least to understand the superficialities of everyday life, and if he does not like it, he still has his group as a place of refuge: a refuge that allows him to be in harmony or dissent. Because of this, he may reach compromises with other members to maintain and to build on his group experience; for it is the group experience that helps the individual crystallize his own being and his existence within an aura of ambiguity.

As depicted in this study, the Madrona work group is a small special kind of group with a special breed of men. However, as one abstracts and conceptualizes the ambivalent nature of man with regard to the contradictions of equality and differentiation, it is not difficult to conceive where one is able to resolve ambivalences, and, in turn, have a chance to be an actor instead of solely reacting to the expected. This work group. 
depicts in its own special way a style of life that has a potential to produce new and unique things. It is in group life where the intensity of being an equal or wanting to be an individual is felt with considerable contradictive impact.

\section{Further Research on Harmony and Dissension}

This study illuminates the importance of further research on the concepts of harmony and dissension. As applied in this thesis, harmony approximates the concept of consensus. Harmony, though, is a conceptualization that encompasses a broader perspective than consensus; harmony being closer to a negotiable or transactional existence with a situation whereas consensus is more specifically oriented toward the sharing of a common experience and/or agreement with other involved participants. If a participant does not want to share common experiences, or does not want to be in agreement with others, he is considered out-of-consensus.

With this concept of consensus stringently upheld in a situation, being out-of-consensus specifically connotes deviancy (deviancy being closely related to abnormal behavior). The usual consequences of this behavior, that is labeled deviant or abnormal, are ostracizing, blatant prejudice, or damaging ridicule. This is not saying that certain kinds of behavior may not warrant the label of deviancy (i.e., murder, beating up old men and women, raping small children, etc.); however, more often than not, the concept of deviancy is used for any mode of behavior that even scratches or hints at being out-of-consensus.

The study reported in this thesis discusses working men's behavior that at times is considered out-of-consensus. Also, the situation the men are engaged in is considered a rather tight and formal situation. 
However, they are not ostracized nor overly ridiculed for abnormal or deviant behavior, since this behavior is not considered 'deviant.' Their behavior is not placed into categories of right or wrong behavior, nor is it placed in categories of normal or abnormal; instead, their behavior is as varied as the situations they participate in and as complex as the personalities they connote.

Being in dissent is quite the opposite to being considered a "weirdo," or a reasonable facsimile to a deviant. Fellow workers do not consider other workers to be out-of-consensus for this would mean the worker is deviating from a well-defined norm; interaction between the workers is a rather tenuous process. The Madrona workers do not consider themselves in-consensus or out-of-consensus with each other. They view each other as being a "maybe": "Maybe he will agree with me or maybe he won't."

The Madrona workers do not always expect consensus or agreement. They do, however, expect to act like professionals while working on a job. They do expect consensus by way of coordination; they do not expect consensus on the remainder of the acts. They will do "their thing" while moving, while the other worker will do his. The Madrona workers say: "What do you know--he does agree with me!" They do not expect consensus. They do like to be in harmony, which is like having an aura of pleasantry encompassing a job. They also like having an aura of excitement and frustration (which is like being in dissent). No matter how deviant the men were during the job, they were always looked on as being "themsel.ves." They did not destroy anything, except a few misconceptions that the customer might have had. 
This notion concerning harmony and dissent is a real phenomenon among people. These notions include consensus, but bypass the negative superficialities of deviancy and this is reason enough to pursue further research in this area. Deviant behavior may be placed on the outermost fringe of a normal curve. However, man is at fault for being too lenient in conceptualizing deviant behavior and consequently the negative repercussions may smother those unique and genuine qualities of dissent. Instead of remaining on the fringes, deviancy begins to craw1 up the slopes of normalcy and the further it crawls, the less man will be able to act. He will, indeed, become plastic. 


\section{BIBLIOGRAPHY}

Berger, Peter L. The Human Shape of Work (New York: MacMillan Co., 1964), p. 228 .

Blauner, Robert. "Work Satisfaction and Industrial Trends in Modern Society," Rienhard Bendix and Seymour Martin Lipset, Class, Status and Power (New York: The Free Press, 1966), pp. 473-488. Blaunder states that the difference in work satisfaction is the nature of on-the-job social relations. . There is much evidence to support the proposition that the greater the extent to which workers are of integrated work teams on the job, the higher the level of job satisfaction (p. 481).

Caplow, Theodore. Principles of Organization. (New York: Harcourt, Brace \& World, Inc., 1964). For instance Caplow mentions that the 'peer group' (a form of informal relations) provides certain satisfactions to its members which they require for the effective performance of their tasks but which the larger organization itself is unable to supply (p. 20).

Evan, William M. "Peer-group Interaction and Oxganizational Socialization: A Study of Employee Turnover," American Sociological Review, 7o1. 28, No. 1, 1963, pp. 436-440. Evan states that the peer group can uniquely perform the function of reducing strains and al.leviating tensions ( $p$. 439).

Gans, Herbert. Uxban Villagers (New York: The Free Preas, 1962).

Goffman, Erving. Encounters (New York: The Bobbs-Merrill Company, Inc., 1961), P. 96 .

Hajda, Jan. "Ambivalence and Social Relations." (Paper read at the American Sociological Association Meeting, Boston, August 26, 1968).

Iit:ak, Eugene, "Technological Innovation and Theoretical Functions of Primary Groups and Bureaucratic Structures," American Journal of Sociology, Vol. 73, 1968, pp. 468-481. One of the reasons for job satisfaction is that "typical dimensions of primary groups as face-to-face, affective and diffused relations provided a communicator with faster feedtack and man; more alternative ways of insuring that the message would be heara" ( $p .470$ ).

Merton, Robert K. and Barber, Elinor. "Sociological Ambivalence," Edward A. Tiryakian, Sociological Theory, Values and Sociocultural Change (Glencice: The Free Press, 1963), p. 95. 
Roethlisberger, F. J. and Dickson, W. G. Management and the Worker

(Cambridge: Harvard University Press, 1939). This, of course, is the famous "Hawthorne Study," one of the primary works that notes the importance of informal relations to job satisfaction.

Sherif, Muzafer and Sherif, Carolyn w. Groups in Harmony and Tension (New York: Octogon Books, Inc., 1966), p. 192.

Turner, Ralph H. "Role Taking: Process Versus Conformity," A. Rose Human Behavior and Social Process (Boston: Houghton Hiflin Company, 1962), PP. 20-41.

Whyte, W. F. Men At Work (Homewood, Illinois: Dorsey Press, 1961), p. 10.

Whyte, W. F. Street Corner Society (Chicago: University of Chicago Press, 1955). 
APPENDIX A

EDITED FIELD NOTES AS FOOTNOTES TO TEXT OF CHAPTER IV

1. During the summer of 1968 I was working at Madrona Transfer \& Storage as a helper and later on as a driver. During the summer Bill and I got into a discussion concerning the trade of furniture moving. He talked about certain technicalities that were involved and had to be learned. However, his main emphasis was on the innovative aspect of loading and hauling. Bill stated that "every job is different--as long as I have been working in furniture, I've never seen two jobs the same." I replied by stating that "it's sort of an artistic trade with them." He laughed and replied "in a way." During the summer of 1969, my actual participation as an investigator, the same topic was discussed with one slight change--"furniture moving as an art" was brought up by Einer, Bob, Jessie, Ron and Bill.

Even when talking to union officials about their contract, the men would compare their occupation with freight hauling (which to them does not require the skill that is required in furniture moving). "We are a trade like bricklaying, carpentry--we are a trade just like they are-and our contract should be like theirs."

2. The subtle distinction between working toward and under a borrowed title was brought out by Bob unintentionally during a household move. Bob kept talking to the customer about the virtues of his occupation; he kept trying to stress the point that furniture moving is different than 
other truck driving jobs. He mentioned the differences between jobs, how he must always load furniture differently from job to job, how he "felt like an artist." During this dialogue both Jessie and Ray were becoming increasingly upset. They kept referring to Bob's 'mouth' as 'flapping too much about their trade." Jessie and Ray told me that it made them feel degraded to hear Bob trying to convince someone that their "work" is better than other kinds of "work." "We just do it, and the customer will make up his own mind."

3. Bob, Einer, and Jim referred to the customer as someone who starts out in a move with a "god-like attitude" toward them. Einer continuously stated that a customer thought of him as "just a truck driver . . . and most people feel that a truck driver is a dumny." "Plug a little funniness into the job," "be concerned about their furniture, no matter how trashy," "don't jerk, be together when carrying two-man pieces," and "don't humiliate team members by being bossy" were all said at some time during the summer of 1969. In a more indirect fashion, "don't be depressing," "don't play on a job," "the customer does not like smart aleck people working for him" all were collected throughout the summer while in the truck cab, in the lunchroom, while working on a job, or in the tavern. And, importantly, observed and experienced by me on a moving job.

4. Both management and customer alike would talk about coordination as being a prime example of good workmanship. "You make it look so easy.," "I remember when we moved in and took a friend and myself a long time to put that wash machine into the basement," are typical remarks made by pleased customers. "You guys looked real good in the Standard Insurance office move; you were organized, and kept the flow of equipment moving without. 
any noticeable jam ups," was a remark made by a person in management in reference to one of the better office moves.

5. There was one job in particular that I became quite aware of a customer expecting seriousness on the part of the movers. Jim and I had gone on a small local move; I was driving and Jim was my helper. Wall, I wasn't in a serious frame of mind that morning, nor did I feel. like acting serious. I had a hangover, which only laughing and lots of humor seemed to cure. Acting serious seemed only to intensify the very distinct sound of crashing waves inside my head. Jim, who goes the way the driver goes, did not help the serious act. Instead, both of us were laughing, joking, and it generally appeared as though we were having a jolly good time at the expense of the customer. We finished the move in the allotted time and went back to the warehouse where Jay* Madrona was waiting with a pink slip (complaint). It just so happened that we were accused of breaking a T.V. set, breaking a lamp, breaking the legs off a chair and playing instead of working. All of this just because we had not acted serious.

However, when seriousness is portrayed, the customer begins to relax. Even though he is relaxing, it does not mean that the mover's status has increased any, for the customer at this stage is still autocratic. "Now, be careful," "why don't you load the piano first?" "why did you put that lamp shade on the top?" are typical customer remarks while still in the first phases of a move. Humor injected slowly, then Increased to a point, was one strategy that was used and seemed to work in developing a friendly mood. However, more of ten than not, humor 
injected sporadically with seriousness being present as an underlying current. When humor is brought in, the customer's bossiness usually diminishes and he becomes more personal. He begins to ask about back stage information on the workers. "You married?" "How 1ong have you done this?" "Do you get a lot of overtime?" "Is there any special way of moving a stove?" etc., were a few recorded customer remarks once humor is injected. Status distinctions between worker-customer appeared to disappear.

6. During jobs, no matter how hard the workers may try, some customers reject.their overtures of humor and friendliness. These customers are considered real "sourpusses," "shits," "big shots," or "mother-fuckers." They continue a constant barrage of orders throughout the move. No matter how hard the workers try to be nice and congenial, it remains a futile effort at establishing themselves as people rather than "laborers." When the workers become aware of this lack of friendliness by the customer, they begin to ignore the customer and entertain themselves. That is, if entertaining themselves is still a possibility. In instances such as this, the back of the truck becomes a livelier place than when the workers are succeeding in stirring up an atmosphere of good will. There is more talking about the customer, an increase in short smoke breaks, an increase in topics of discussion, etc. The back of the truck is an excellent example of 'backstage' behavior when front stage behavior is failing to receive the reactions it usually receives.

7. The workers' conception of a 'good move' is about as varied as the number of workers belonging to the Madrona work group. Even amongst the individual workers the definition of a good move changes. At one moment 
Bob thinks he did a tremendous job; however, he does not receive a 'tip'; he then becomes dissatisfied with the customer who was perfectly congenial throughout the job. At another job, everything stays constant in relation to friendliness, no damage, customer respect, etc., but no tip is mentioned by Bob and he thinks it was a 'good move.' While I, as his partner, interpreting the first one as bad because Bob was talking too much and wasn't concentrating on moving furniture, did not expect a tip. Through the summer of 1969 , there was one move that I participated in that all team members agreed was a "damn good move." The team consisted of Bob, Ray, and Vance. We moved a very rich lady from one beach house to another at Salishan (a private beach for very wealthy people to build their own little [sic] beach cabins). We wore our best uniforms, starched, pressed, and Madrona patches in the proper places. Before the job started, she already had a reputation as a generous tipper.

Bob, who, prior to this move appeared incapable of issuing nothing but orders, was giving and taking advice all day 1ong. Bob, who also appeared to be a 'mouth' in other moves, was quite content in being a mover in the more fashionable quiet manner. Ray, who has his ups and downs, was on a very apparent up during this job. Maybe because this lady was nice and a very gentle person, Ray was subdued into a state opposed to his usual boisterous, loud self. Before the job, I had seen the acts, but in this move the acts were so personified that a layman would have a difficult time in avoiding the constant and blatant appearance of them. Never before had I observed Ray and Bob so diligently giving each other advice in such a friendly fashion. This is the only move that $I$ had and would see them get along, at least superficially, so well. There was a sense of everybody participating; even the nice and gentle lady we were 
moving was very much a part of this manifest drama in moving. "We got twenty bucks a piece for our superb performance."

8. Since an 'overfit' is invisible just by its definition, I will use my own personal experience while working on a job, and simultaneously trying to differentiate myself within the bounds of advice and humor. During a household move, I was the driver and Ray was the loader. Knowing my lack of experience and realizing Ray's experience and hatred of autocrats, I decided to bring a little humor in while giving advice on the next piece I wanted Ray to bring me. I walso wanted to show Ray how much I had learned and in a way have him reply, "good boy." So I was standing there and said in a tone of voice that Ray would have used: "Stuure, he can do it! Suuure the mother-fucker can load this truck--go get me that PIANo!" Ray replied, without a grimace or a grin, "Okay, let's go." The response I wanted and what I got were two entirely different things. I mean, I got nothing in return for what I thought was a beautiful mimicking job, with some advice to get the job done, and with an excellent choice for the next piece--nothing happened!

9. The misfit act in this group, at least while working on a job, is not a difficult accomplishment. Bob, of course, has already gained notoriety for his 'misfit acts.' It is apparent when Bob gets on one of his rampages about the virtues of furniture moving that he is attempting to gain recognition and acceptance from the other workers by convincing the customer that he is in a "good profession." However, as mentioned in Footnote 2, he receives a bad reaction from his fellow workers when he starts playing this game. 
10. Ray, with his rapping humor, once established in a job, was the leading expert in making acts 'just fit.' Once he was able to initiate his rapping humor, he could make just fit into any situation that allowed its entrance by changing a few words. For example, during an office move, he could say "Poor girl! has on a blue dress! poor dress!" or during a household move, "Poor Mrs. Robinson* has a husband! poor husband!" He always seemed to get the recognition and acceptance that he wanted through his special brand of humor.

Many times, giving advice while moving an awkward piece of furniture would be recognized and accepted. For example, while moving an upright piano up a flight of stairs that were very steep and narrow, Bill brought in an old idea (but new to the rest of the team members). Since only one man could take the front, or the end next to the ascending steps, and two men could take the back, one low and one high, the front man could not lift the front by himself and move it toward him up one stair at a time without crushing his feet. Bill got a heavy duty strap, wrapped it around the base of the piano, and slung it around his shoulders. In this manner, he could use his full body to lift while being one step above the piano. This idea looked good, was beneficial tc the other team members, and he was congratulated for its re-appearance. When he was congratulated, Bill's face, which was usually placid, turned into a slight grin of approval.

11. Figure 5 was constructed from my own interpretation and experience on each of the types of jobs, and the structural characteristics of each. I also talked with Jay Madrona about differences in jobs. He helped 
substantiate two of the acts frequency in the types of jobs: coordination and seriousness. However, it was the other two acts that I interpreted as being variant in relation to type of job.

12. Many of the choices that are discussed here are alternatives that were experienced by me and impressions that I got from other workers. when talking about certain events that occurred during a job. There are instances on a job where a person wants to stay as inconspicuous as possible. In other words, if things are going wrong at times, you want to play it safe and not say anything. Or you may be in a terrible mood that day, and you just don't feel like doing anything except get by until the $j o b(s)$ and the day are over. Jessie said that sometimes you just know that anything you may want to say may be taken wrong. Bob said, "I just can't understand why Ray doesn't like me; I'm a good household mover--I must be since I always get the bad one: I let the customer know who is boss, and still he gets mad at me. I just don't know." The impression that I got while Bob was relating this to me was that Bob makes choices between acting and playing it safe, and he is bothered by the former because he feels he is doing the proper thing. However, Ray just doesn't grant Bob the recognition and acceptance Bob apparently wants.

13. This was not a frequent occurrence with regards to the Madrona work group while working on a moving job. However, a good example of too much recognition was a frequent occurrence while working in the warehouse. Probably because the work is so boring in the first place, the men who are involved may feel that you must keep up some kind of motivating force. "Good job, Ray," "You sure stacked those tires in a nice straight pile," 
or "You are sure getting that glass unloaded in a hurry"; statements like these were quite frequent in the warehouse and you may feel good for a while, but after a time they became meaningless; they had no impact on your psyche; you just became increasingly bored.

14. During a household move Ray got terribly mad at Bob. I was also on the same move. Interestingly, this move was just after the Salishan 'good move' (Footnote 7). At the beginning of the move Bob and Ray seemed to be getting along. However, just as Ray and I were attempting to coordinate our efforts, Bob, who was loading, gets out of the truck (probably getting impatient with our initial slowness) and begins in a huffy manner to haul and load furniture. This act by Bob destroyed the pace that Ray and I were attempting to establish. Ray got quite mad, both verbally and non-verbally. Verbally he called Bob a "no-good-son-of-a-bitch," etc., and non-verbally he did the speedup routine in hauling the furniture. In a very short time the back of the truck was filled and furniture was spilling out the back onto the lawn. Bob responded by asking, "What the hell is wrong with Ray?" Inevitably, a footrace began between Ray and Bob: Bob not knowing why Ray was mad and getting himself mad, and Ray knowing why he was mad and not telling Bob and getting madder because Bob was working faster. I was caught in the middle attempting to slow them down because I was getting tired.

A spontaneous act like saying "shit" in front of a customer may draw negative responses. During an office move I was helping move a file and my fingers got a little crunched between the file and the wall. I responded in a somewhat spontaneous fashion by saying, in my loudest whispering voice, "Shit fuck! That ouches!" There were a few girls that were still working at their desks at that moment and a couple of them 
looked up with shy, disapproving grins. Einer, who was at the hand truck, transmitted a glare that appeared to say "I disapprove." I really didn't care.

15. There has been a lot said about Ray's rapping humor; however, very little has been said about facial humor. Facial humor took hold as a kind of humor directed between workers or behind customers' backs. For instance, a "bossy" customer may be directing a team member and you may be standing behind the customer; you curl your lips, slant your head, and wrinkle your eye brows in view of your team mates. The results are quite funny for your team mate who is "being directed by the customer," and he must maintain his composure. Also, while carrying extra heavy items, facial humor helped alleviate some of the weight and strain in carrying such a piece. At least for me it did.

16. In the initial stages of a household move Bill would get upset with Ray if he began his "how come," "suuure," etc., mode of humor. This humor was okay once the men established coordination and then Bill would laugh along with everyone else. However, Bill would become noticeably upset with Ray and tell him to keep his mouth shut if he tried it while still trying to get the job moving.

17. Refer to Footnote 2 about Bob, Besides that discussion, Jessie also mentioned that "Bob is always holding up the move" and that he should "quit yapping."

18. One office move in particular fits this description to a tee. It was an office-warehouse combination move. This firm stored and sold all sizes, shapes, and weights of electronic equipment. This move began on 
Thursday and ended up on Friday night. Thursday morning one three-man team went over and began to load office equipment and the rest of Thursday men would be sent over and taken away, depending on the need of other more immediate jobs. Friday, the whole crew went over to complete the job that day. Jay Madrona, Joe Zenner, and Einer were supposedly going to lead this office move. The contradictions began inmediately. They could not establish and stabilize the teams, Not only were all three contradicting themselves, but Jay was contradicting himself. One minute I was assigned to the vault trolleys---the next I was running after lumber for support and a quick minute later I was told to help 1oad. Besides me, Jessie; Bob, and Ray were also going through this "run, skip, and jump but I don't-know-where routine." The office workers were watching and we felt like real fools. One of the office managers for this electronics company made a comment on "how much better Einer was than that guy in the flowered shirt (Jay). By the way, who is he?" I was hesitant in answering that question.

19. Einer, Jessie, Bill and Ray (when he wants to be) would be considered leaders. Not constant, but they did appear quite frequently when called for by other members. They would not arise simultaneously, but if one did not feel like being a leader, the worker(s) would shift to another. Somewhere along the line one of those would meet the demands made of him the best he knew how under the circumstances.

20. During that particular office move at the Electronic firm, the whole morning was a "confused mess." Einer was mad, and had lost his usual cool. When Jim and Bob and I went to him for instructions, he responded by saying, "I don't know what the hell is going on." Bob immediately 
tried to take over by stating, "I'11 load the trailer on Burnside and you two empty the offices." However, that little act of leadership did not pay off for along came Jay Madrona, in a highly excited state, yelling about the lack of teamwork, and in the same breath saying, "Cannucci, take Mo's pickup and go get some $2 \times 4$ 's at the warehouse." John (who had never been on an office move prior to this time) and a temporary helper were standing, just standing, a few feet away while Jay was making the utterance. As I was jogging to the pickup, I overheard Jessie asking John and the other guy if they could help latch the bins. together so that the vault trolleys could be used. Jay replied that he wanted them just to stand there as he had something else for them to do (what, I never did find out). However, when I got back (about 15 minutes), nothing had changed except John and the other guy were latching the bins together. Einer was showing them in what order they should be latched, and Jessie was showing me how to work the vault trolleys, and Jim ( I don' $t$ ' know who was with Bob at that time) was being shown by Jessie how the strap connects between the trolleys. Besides us there were three others standing there. Suddenly, Jay's voice came rolling through the building, "Hey, Cannucci, help Bob load that truck on Burnside." Jessie said, "Fuck him; you other guys go help Bob." Basically this is the way that the move went all morning. There was anger and frustration in the air between workers and management, and eventually between the workers themselves.

The picture above gives a brief chain of events of how this momentary leadership works. All of the above happened in about a half hour period. This kind of leadership is short, succinct, and sporadic. It usually. works. Basically this is the way that it works. Maybe because . 
no one really knew what was wrong, they were ambivalent in choosing any drastic line of action, thereby not being able to alleviate the tension that was being built up in being ambivalent.

\section{During my first summer (1968) working at Madrona there was a guy} named Gill, who apparently thought he knew the tricks of the trade. He immediately began to build a bad reputation with the other guys. During an office move he was helping hold and balance a fireproof filing cabinet. One man was operating the handtruck and Gill was walking backwards, bending slightly at the waist pulling the bottom of the file. (Now, prior to this time he had been given constant warnings about being a clog.) Anyway, something happened and the file flipped up and crunched Gill's toes. It was quite painful, partly because he had worn, of all things, leather thongs that day.

Fortunately I was only a clog once and that was my first day at work for Madrona. I was Mr. Joe College, and I considered myself one step ahead of these furniture movers ( $I$ think at that time I referred to them as "house movers"). This first job was an office move. I was working hard doing whatever I was told to do. When I had completed these jobs, I would chit-chat with the office workers. "Hey, new guy (I remember that so distinctly), come over here," shouted this giant (who I later learned was Don, the number one driver, and who later was to become a great friend) about twenty feet away, with one finger pointed at the top end of a conveyer that was transporting medical supplies from the basement to be stacked and then handtrucked to one of the waiting vans. The giant, with a cool look, said, "New guy, you have a lot to learn . . so you, work here and stack!" My first day, six hours on that conveyer, 
box after box, two feet between boxes, "charlie horses": I learned my lesson fast.

22. At the beginning of a household move early one morning, Jim [sic] was his usual friendly, happy self. The people that we were moving were quite elderly and they had few possessions. The little old lady asked us to be very careful with an old, decayed-looking trunk. Jim responded in a most serious manner by doddling over the trunk as though it were a precious thing to him, as it undoubtedly was to them. He kept doddling and saying, "My, what a fine antique finish it has (there were cracks in its finish, it was scuffed and chipped in many places). This must be quite an expensive trunk. It must have cost thousands of dollars" (it cost $\$ 40.00$ when one of their parents had purchased it). I was a little embarrassed about Jim's performance. It was quite apparent from the old lady's face that she was upset. This is what is meant by intensifying an act to the point of ridiculousness.

23. During one office move, Ray began with his humor in front of the office personnel. It was received in a hilarious fashion. However, Ray did not stop and then wait for another opportunity (which he usually did), but he kept 'rapping' his dialogue of humor continuously. He did not itensify it, but just kept doing it. Einer told him to "shut up," but Ray just laughed and continued his rapping humor. The crew took a coffee break and still Ray continued on with "suuure that," suuure this," and "poor that," "poor this," etc., on through the coffee break, through the next work period, and through 1.unch. Einer, Jessie, Jim and I were getting a little perturbed--all of us at one time or another told him to stop. We were starting to feel like real "dummies." Einer stated that, 
"Ray is making us look like real dumb truck drivers." Ray continued this until late afternoon and he finally slowed down--"Ray either got tired or whatever was bugging him no longer bugged him now." 
APPENDIX B

ON THE METHOD OF PARTICIPANT OBSERVATION

Participant observation as a method of gathering data in the real world is a very trying, difficult, time-consuming and energy-expending one. However, it has one quality that far surpasses any other known method, and that is its flexibility. Participant observation has the capacity to be as flexible as the person who is utilizing the method. In many ways this is considered a handicap in relation to validity of the gathered data, and the eventual analysis of the data. Critics will state that the data is biased and the analysis of the data is pure fiction. These same critics look at research as a structure where you have a definite problem, definite variables, and can predict certain results. Their whole research method is geared and structured around definable social phenomenon. Those researchers will control for bias by picking a particular population and comparing it with another that is supposedly different. They rely on their sampling. However, if something odd happens in relation to their predicted outcome, they usually do not have the resources, time or flexibility to seek out that oddity. It remains undefinable. When they write up the results of their investigation, they emphasize their consistency between problem, data gathering mechanisms, write up. How "objective" they are is a virtue they like to highlight. They usually end with the statement, "this study still needs further research." 
My study also needs further research; further research that will really highlight the dynamic quality of people interacting; further research that will illuminate the ways in which man succumbs to, compromises with, and battles the societal structure he encounters in everyday life. To seek out, understand, and explain this constant struggle, there is only one presently available method that offers one the flexibility to deal with and cope with the dynamic interplay between men and their society: participant observation.

Mistakes and errors in judging an event are common occurrence to a participant observer. However, it is up to hin to make sure that what he saw, and what he experienced, are not just unique with him. At the least, he must know that the people he is observing also see and experience a similar reality. To accomplish the seemingly simple task, but in actuality a highly difficult one, he must be considered an in-group member. As an in-group member he, in turn, must not lose sight of his objectives. In other words, he must maintain a flexibility that allows him to change directions in seeking out relevant data. Below is a description of the flexibility of the dilemmas that arose and how they were dealt with during the process of being a participant observer.

At first I felt that I could make a typology of overt and covert acts within the categories of harmony and dissent. That is, I would become very specific in naming sub-types of verbal and gestural acts for each individual worker under the categories of overt and covert acts. In that way I would be able to catch the acts of harmony and dissension and at the same time give them a meaningful operational definition. However, as I soon learned, I had enough problems in just attempting to keep up with overt acts of dissent and harmony. The covert or hidden acts 
existed, but to type them would have been an even lengthier and complicated process. Maybe, at a different time, this typology of covert and overt acts would be warranted; however, as my observations and notes increased, I became aware of the verbal aspect of this group. If there were any antagonisms or friendliness at any one moment, the members of this particular working group more often than not let it be known with overt verbal acts. In other words, I did not have to unfold any subtleties to gain the meaning of an act.

This brings me to an advantage of being an involved observer. In any group there are certain norns and sanctions that must be learned to become a member. Also, if you are an outsider to the semantic peculiarities that exist in specialized groups (as occupational groups are), you may miss or even worse, misinterpret, member interaction. In being an involved observer you must learn and be sensitive to group taboos; plus an even more difficult task is that of learning a particular group's language. Not that the words are so terribly different, but it is the applied meaning that varies from person to person, from group to group. However, by becoming involved, you are interpreting 'other's' actions much more accurately than the investigator that is attempting to interpret incoming data from outside a group.

Of all of the problems of observing at the interactional dimension, one stands out as being at disadvantage for an involved observer: that is what I call the 'emotional groove.' First, by being involved, you are in part a member of that group and by being a member, you feel all those emotional things that happen in a group. Second, because of this emotive aspect, you channel your observations toward specific episodes of interaction. That is, those things that are disturbing or unifying a group 
are selected out by the member-observer and factors that may have an influential quality are neglected for the sake of involvement. Focusing in on specific events has a consequence of narrowing one's participation into emotional grooves. When an observer gets caught in an 'emotional groove,' he may inadvertently present value-oriented alternatives that may disrupt a somewhat harmonious process. For instance, my first exposure to the union officials occurred around the first part of the summer.

At that time they came to the Madrona warehouse to seek out new workers and tardy members. Anyway, they caught me, and in so many words told me I had to pay dues within two weeks or else they would demand my removal.

Their authoritative response to my questions produced an ascent of anger. I did not vent the anger at that moment since I recollected that participant observation calls for a certain degree of objectivity, However, when the union officials caught a fellow worker on the grounds of tardiness and demanded that he pay an exhorbitant amount of noney immediately--or else--I vented. I began a long value-laden, antiunion dialogue that encompassed many episodes over a several day period.

The realization of this emotional groove placed me into a problematic dilemma from which several questions arose. How much influence would this have on the remainder of my observations? How many other things had I missed while caught in this emotional groove? How many other episodes had I missed because of my mad search for apropos situations where I could vent my anti-union dialogue? Probably the most important question concerns my fellow workers' attitudes over this seemingly unfair incident, since I did not give them the opportunity to express themselves first. It was during this early phase of my observations that I became aware of thọse unanswerable questions and it was from that phase on that I made a conscious attempt to restrain myself from again becoming lost in the 
'emotional groove.' As we enter into the dimension of realism, we will see that this ernest effort was quite futile.

REALISM: Realism in my study was and still is a main concern. I defined realism as explicit behavior patterns emerging from group members whose permanence has established or has the propensity to estabiish informal relations. The first part of the definition 'explicit behavior patterns' was and is a major concern in relation to this realistic dimension. Instead of observing from the outside, I felt that to capture the empirical significance of ambivalence, I must go inside as a partjcipant observer. I must become a member of this working group and interpret behavior and events the same as my fellow workers did. However, as noted above, under the interactional dimension we found out that one may hinder his investigation by being caught up in an 'emotional groove!' I then stated that one has to remain consciously alert so that he doesn't get blindly trapped into a groove. With this statement we then have a problem emerge in relation to my definition of 'realism.' It becomes apparent that if I attempt to maintain some type of neutrality as a group member and sociological observer, I would lose that reality I had defined for my investigation. I attempted the neutral approach with very little success. I found myself desiring involvement in the group on one hand, and separateness on the other. No matter how hard I tried, I would find myself becoming locked into the corpus of the group, for the purpose of equality and confort, then bouncing out of this groove and striving for differentiation on the grounds of a 'good furniture mover,' 'good beer drinker,' 'strength,' and/or 'student sociologist' (in that order of occurrence). In other words, I found myself as a very 
basic part of that concept which I was investigating--ambivalence. I desired the counter-tendencies of status equality and status differentiation just as much as my fellow workers. If I became aware of the strain when one of these tendencies was not being met, I would orient myself towards that which I perceived as blocking it and suddenly get 'lost in an emotional groove.'

In part I was an actor influencing many of the decisions towards seemingly unknown consequences; yet, another part of my behavior was a reaction to certain demands of group members; and, then there was the part that stood back and observed, attempting to make sense out of the ambiguity and confusion. My interpretation of the acts and events are a combination of all of these different aspects of observation. The problem is that I don't know how close my interpretation nears the definition of realism that I had set as a goal. However, I do feel that I neared the definition much closer with this method of participant observation than I would have with any other krown method of investigation.

The discussion above illuminates the flexibility of being a participant observer. It, however, does not really emphasize the mindprobing process of being objective and/or subjective in evaluating incoming data. The frustrations and anxieties that arise cannot be described. In many ways being a participant observer parallels a "soulsearching trip" that has all kinds of repercussions to one's psyche. To become involved and still maintain some objectivity, is not easy. The only way such an experience can be shared is if the reader has experienced the same kinds of things. Below is another aspect of participant observation that I believe is very important: it is the time dimension. 
TIME: I blocked my observations into three phases of time: theorymethod phase, which consisted of establishing an analytical framework and a method; fact-finding phase--the actual observations of events and acts; and, categorizing-writing phase--the categorizing of notes and writing of thesis. These three phases fit almost any method of investigation except that the time spent on all three phases in participant observation exceeds any other method.

Participant observation is a slow, painstaking method that consists of long days over a long period of time. However, it does contain that exciting quality of being involved in a social process where actual events are taking place. As I left the phase with the theoretical framework of ambivalence, I excluded the concept of a normal behavior; for example, if a worker did not act in accordance to certain normative expectations, he was considered a deviant. Instead, I took the view that there are built-in antagonisms in the structure, or more appropriately, there are counter-tendencies that exist in the structure of this work group. This implies that a group member could become an offender rather than a 'deviant.' Further, implications are that since he is an 'offender' rather than a deviant, he would still be an intrinsic part of that group. This in turn helped me as an observer to orient myself towards internal process of change, compromise, and transactions. With this in mind, I applied boundaries to this working group so that I could limit myself to internal happenings which would also help me be aware of certain overt external influences.

As I became involved in the 'fact-phase,' the dimension of time became overwhelmingly important. For instance, even though I had a fairly clear picture of this working, I had misconceived the importance of the 
union during ny first phase. This called for a re-orientation on my part (at least at that time I felt I had reached a real dilemma). The topic of the union was consistently present in episodes of interaction and it became increasingly clear that something was disturbing this working group. This, in conjunction with the problans of involvement (emotional groove) and realism, left me in a phase of confusion and disorientation. I was grabbing at anything for explanations. I had lost my theoretical perspective and was becoming quite a disillusioned observer. Time was flying by and I felt that I had gotten nowhere in my investigation. I could not locate any consistent patterns. It was as though someone dropped a barrel of pingpong balls and I was wildly scrambling around to gather them all in. I felt I needed more time--not three months but three years. However, toward the latter part of the summer (end of the fact-phase) patterns began to emerge from my notes and for me the actual. events were beginning to consist of behavior patterns. However, overt external influences were also staring me in the face. Two of the external variables that became most dominant were the union and the management.

These overt categories I called signs of disturbance were dominant: in the first part of the summer, and signs of restoration were emerging in the last part of the summer. Running parallel with the signs were those interactional things that I categorized as acts of dissent and acts of harmony. From this point on I began looking over my notes for empirical evidence to support the ambivalent nature of my status equality and status differentiation as affecting this process.

As I began to look at the data and set it into a scheme for presentation, I came upon the stark realization that I would have to exclude 
management and union as inportant variables influencing the internal work-ings of this work group. Instead of a short succinct thesis, I would end up with three volumes on the Madrona work group. Decision after decision had to be made. I finally made the decision to concentrate on just the work group members. Part of this decision was made as I actually began writing up the findings. If, indeed, the counter-tendencies of status equality and status differentiation do function among the eight men who belong to this work group, I would have plenty to write about.

In other words, from the beginning to the end of the investigation there is a continuous narrowing down process of your problem, your varjables and your results. During this process there are many decisions to make. The end result is then the outcome of one long, frustrating decision-making process. Even at the end, you still wonder if you made the right decisions.

One problem that stared me in the face was removing the complexity of human interaction from its actual place in time and space and transposing it onto a piece of paper. Something will be lost, or excluded for the sake of convenience, simplicity and/or writer's ignorance. It seems that once an observer is removed from his involved participation, he reaches a dilemma of relevance; that is, he must make choices in relation to the relevance of his notes as singular events that he can or cannot fit into his scheme as compared to a chain of events that are relevantly related that may not fit so neatly into his scheme. For the sake of clarification, one event may be exaggerated to the point of distortion which, in turn, would reduce the related events to triviality. 
The whole procedure of writing up a participant observation is problematic. You have a large number of field notes that have been loosely categorized during the actual participation. Some of the events have direct bearing on your analysis; however, to present them would involve a lengthy discussion in showing their relationship. For example, the union has been mentioned several times. However, its relationship with the work group has never been established. Even though I had narrowed down my problem, and the relationships, so I could realistically discuss what happened in the work group. I did not account for the efrect that the union may have had on the interpersonal relations among the men. For example, factions formed during part of the sumner, one strongly union oriented and the other more neutrally oriented. The former wanted more union control in Madrona Transfer \& Storage (who had successfully fought off the union bid for more power) and the latter desired the traditional union involvement. Even though the factions would seemingly dissolve while working on a move, it was difficult to determine how much of the dissension arose through this internal strife.

Fortunately, the workers came together the latter part of the summer when they elected Jessie as their shop steward. Prior to this, Chuck, a warehouseman, was shop steward and because of his lack of knowledge concerning the occupation of furniture moving, he opened the door to a lot of back stage information concerning the breaking of union rules between workers and management. He became increasingly disliked. The factions began a long and lengthy dialogue concerning his qualifications as a shop steward. They finally resolved the issue by agreeing that "he simply doesn't understand us or our work." By subtle pressure, some intentional, and some unintentional, they drove him out and elected 
Jessie.

It was this kind of information that was excluded for the sake of consistency, time, and tightness. And, as an end result, you end up with some structure. However, as compared to other methods of research where you have structure from beginning to end, participant observation has produced enough alternative ways of looking at a social phenomenon that you are never satisfied with your end results. Something else is always missing. 